\title{
Screening for chlamydia and/or gonorrhea in primary health care: systematic reviews on effectiveness and patient preferences
}

\author{
Jennifer Pillay ${ }^{*} \mathbb{D}$, Aireen Wingert, Tara MacGregor, Michelle Gates, Ben Vandermeer and Lisa Hartling
}

\begin{abstract}
Background: We conducted systematic reviews on the benefits and harms of screening compared with no screening or alternative screening approaches for Chlamydia trachomatis (CT) and Neisseria gonorrhoeae (NG) in non-pregnant sexually active individuals, and on the relative importance patients' place on the relevant outcomes. Findings will inform recommendations by the Canadian Task Force on Preventive Health Care.
\end{abstract}

Methods: We searched five databases (to January 24, 2020), trial registries, conference proceedings, and reference lists for English and French literature published since 1996. Screening, study selection, and risk of bias assessments were independently undertaken by two reviewers, with consensus for final decisions. Data extraction was conducted by one reviewer and checked by another for accuracy and completeness. Meta-analysis was conducted where appropriate. We used the GRADE approach to rate the certainty of the evidence. The Task Force and content experts provided input on determining thresholds for important effect sizes and on interpretation of findings.

Results: Of 41 included studies, 17 and 11 reported on benefits and harms of screening, respectively, and 14 reported on patient preferences. Universal screening for $C T$ in general populations 16 to 29 years of age, using population-based or opportunistic approaches achieving low screening rates, may make little-to-no difference for a female's risk of pelvic inflammatory disease (PID) (2 RCTs, $n=141,362 ; 0.3$ more in 1000 [7.6 fewer to 11 more]) or ectopic pregnancy (1 RCT, $n=15,459 ; 0.20$ more per 1000 [2.2 fewer to 3.9 more]). It may also not make a difference for CT transmission (3 RCTs, $n=41,709 ; 3$ fewer per 1000 [11.5 fewer to 6.9 more]). However, benefits may be achieved for reducing PID if screening rates are increased ( 2 trials, $n=30,652 ; 5.7$ fewer per 1000 [10.8 fewer to 1.1 more]), and for reducing $C T$ and NG transmission when intensely screening high-prevalence female populations (2 trials, $n=6127 ; 34.3$ fewer per 1000 [4 to 58 fewer]; NNS 29 [17 to 250]). Evidence on infertility in females from CT screening and on transmission of NG in males and both sexes from screening for $C T$ and NG is very uncertain. No evidence was found for cervicitis, chronic pelvic pain, or infertility in males from CT screening, or on any clinical outcomes from NG screening. Undergoing screening, or having a diagnosis of $C T$, may cause a small-to-moderate number of people to experience some degree of harm, mainly due to feelings of stigmatization and anxiety about future infertility risk. The number of individuals affected in the entire screening-eligible population is likely smaller. Screening may make little-to-no difference for general anxiety, self-esteem, or relationship break-up. Evidence on (Continued on next page)

\footnotetext{
*Correspondence: jpillay@ualberta.ca

Alberta Research Centre for Health Evidence, Faculty of Medicine and Dentistry, University of Alberta, 1140587 Avenue, Edmonton, Alberta T6G 1C9, Canada
}

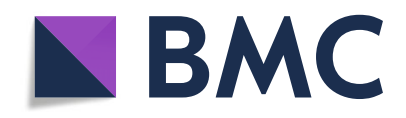

(c) The Author(s). 2021 Open Access This article is licensed under a Creative Commons Attribution 4.0 International License, which permits use, sharing, adaptation, distribution and reproduction in any medium or format, as long as you give appropriate credit to the original author(s) and the source, provide a link to the Creative Commons licence, and indicate if changes were made. The images or other third party material in this article are included in the article's Creative Commons licence, unless indicated otherwise in a credit line to the material. If material is not included in the article's Creative Commons licence and your intended use is not permitted by statutory regulation or exceeds the permitted use, you will need to obtain permission directly from the copyright holder. To view a copy of this licence, visit http://creativecommons.org/licenses/by/4.0/ The Creative Commons Public Domain Dedication waiver (http://creativecommons.org/publicdomain/zero/1.0/) applies to the data made available in this article, unless otherwise stated in a credit line to the data. 


\begin{abstract}
(Continued from previous page)
transmission from studies comparing home versus clinic screening is very uncertain. Four studies on patient preferences found that although utility values for the different consequences of CT and NG infections are probably quite similar, when considering the duration of the health state experiences, infertility and chronic pelvic pain are probably valued much more than PID, ectopic pregnancy, and cervicitis. How patients weigh the potential benefits versus harms of screening is very uncertain (1 survey, 10 qualitative studies); risks to reproductive health and transmission appear to be more important than the (often transient) psychosocial harms.

Discussion: Most of the evidence on screening for $\mathrm{CT}$ and/or NG offers low or very low certainty about the benefits and harms. Indirectness from use of comparison groups receiving some screening, incomplete outcome ascertainment, and use of outreach settings was a major contributor to uncertainty. Patient preferences indicate that the potential benefits from screening appear to outweigh the possible harms. Direct evidence about which screening strategies and intervals to use, which age to start and stop screening, and whether screening males in addition to females is necessary to prevent clinical outcomes is scarce, and further research in these areas would be informative. Apart from the evidence in this review, information on factors related to equity, acceptability, implementation, cost/resources, and feasibility will support recommendations made by the Task Force.
\end{abstract}

Systematic review registration: International Prospective Register of Systematic Reviews (PROSPERO), registration number CRD42018100733.

Keywords: Systematic review, Chlamydia, Gonorrhea, Screening, Sexually transmitted infections, Guideline, Patient values and preferences

\section{Background}

\section{Impact of the infections}

Chlamydia trachomatis (CT) and Neisseria gonorrhoeae (NG) are the most commonly reported bacterial sexually transmitted infections (STIs) in Canada [1, 2]. In 2017, CT was reported for $0.6-1.3 \%$ of males and $1.1-2.5 \%$ of females $15-29$ years old, and for $<0.4 \%$ for those above 30 years old [3]. NG rates are about one-tenth of CT $[1,2]$. These annual reported cases are thought to underestimate actual rates by at least 70\% [4], likely because the infections are largely asymptomatic, often treated using syndromic management, and are incompletely reported [4]. Additionally, without widespread testing of extragenital sites, reported rates generally reflect genital infections whereas oropharyngeal and rectal CT and NG infections can be as high as 20\% and often occur in the absence of a genital infection [5-7]. Lastly, lower reported rates in 15-19 year olds compared with 20-24 year olds, and in males, are attributed to lower testing rates rather than true differences in prevalence. Screening studies have reported much higher rates in 15-19 year olds and similar rates between sexes $[8,9]$, which aligns with knowledge about behavioral (e.g., condomless sex [10]) and biological (e.g., cervical ectopy in adolescent females [11]) risk factors. Several sexual behaviors such as inconsistent condom use, multiple sexual partners, and partner(s) having concurrent partners place one at higher risk. Although the total number of cases is relatively low compared with other provinces and populations, the highest population-based prevalence rates in Canada are observed in Nunavut and the Northwest Territories and for Indigenous peoples [4].
These rates may reflect the relatively high impacts on several social determinants of health such as socioeconomic status, geography, demographics (younger median age), and other aspects of social vulnerability including colonialism [12]. There is also concern about the lack of access to screening as well as to culturally safe care especially in rural and remote regions. Some individuals (e.g., MSM, transgender) are disproportionally impacted because of a delay or avoidance of seeking STI-related information, care, and services as a result of anticipated homophobia, transphobia, ignorance, and insensitivity [13]. Having other STIs is also a risk factor. Up to 20 to $40 \%$ of individuals infected with NG are co-infected with CT, although fewer people $(0.6-10 \%)$ with CT also have NG [4, 14-18].

Rates of CT and NG increased three-fold and five-fold, respectively, between 1997 and 2017 in Canada, with steady increases in CT and more accelerated increases in NG over the last 5 years [3]. These rises to some degree reflect increases in case finding, from the use of highly sensitive (86-98\% [19]) nucleic acid amplification tests $[1,2]$, the availability of urine and self-swab sample collection, and increased screening of extragenital sites. There is also a hypothesis that the increased rates of CT are paradoxically due to increased reinfection rates following aggressive control efforts "seek and treat", due to an "arrested immune state" associated with early initiation of treatment resulting in interruption of naturally acquired immunity [20].

The mean duration of CT is 1.4 years [21] and of NG is about 6 months [22]. The infections will resolve spontaneously if not treated, but while active, they can initiate inflammatory and immunological processes leading 
to several complications [23]. In females, CT and NG are important causes of pelvic inflammatory disease (PID), with CT implicated in one-fifth to one-third of all PID cases [24-26]. PID can be asymptomatic, resolve spontaneously, or lead to the sequelae of chronic pelvic pain, ectopic pregnancy, and infertility. It may also be possible for the infections to cause ectopic pregnancy and infertility without first causing PID [27]. Best estimates of the rates of complications in untreated CT, from longitudinal cohorts and control arms of representative trials, are $10-16 \%$ for PID [28, 29], 3-8\% for chronic pelvic pain [27, 30], $0.02-2 \%$ for ectopic pregnancy, and $0.1-4.6 \%$ for infertility [27]. Infection with NG results in more severe manifestations and increases the risks of PID and its sequelae [31]. The duration and severity of these outcomes will vary [32]. In males, reproductive system complications include epididymitis, with or without orchitis, and, rarely [33], infertility. Other complications occur in both reproductive (e.g., urethritis, cervicitis) and non-reproductive sites (e.g., reactive arthritis, pharyngitis, proctitis) for both sexes. An uncommon complication of NG is disseminated gonococcal infection, thought to occur in $<1 \%$ of those infected and with the rare sequelae of endocarditis [34]. CT and NG may increase susceptibility to the human immunodeficiency virus (HIV), although findings from longitudinal studies examining the associations between STIs and HIV acquisition have inconsistent findings, due to poor accounting for actual HIV contact/exposure and adjustment for confounders; moreover, trials have failed to demonstrate that STI control interventions can reduce HIV incidence [4, 5, 35-38]. Reinfection with CT or NG increases the risk for complications [27, 39-41]. A meta-analysis of 38 studies found median reinfection rates for CT of $13.9 \%$ (follow-up 2-60 months) and for NG of $11.7 \%$ (follow-up 3-20 months) [39]. Little is known about the reproductive consequences from single-site extragenital CT infections, although oropharyngeal infection can be transmitted to the genitals [42], and infection of the genitals may occur through contiguous spread from extragenital sites [43]. Current treatment regimens for uncomplicated urogenital CT and NG are over 95\% effective [44-48], if adhered to, although antimicrobial resistance is becoming a major issue for NG [49].

\section{Screening for $\mathrm{CT}$ and NG}

Because of the largely asymptomatic nature of the infections, screening may be necessary to reduce the clinical consequences discussed above related to the natural course of infection. Screening refers to systematically offering a test to detect an infection in those asymptomatic or not purposively seeking care for symptoms. It includes the associated follow-up including treatment and partner notification, as well as possibly re-testing for re- infection and counseling on future STI prevention. At a population level, the aim of screening is also to reduce transmission of the infections. However, screening might lead to negative physical (e.g., serious adverse drug effects from treatment) or psychosocial (e.g., stigma, anxiety) consequences. Possible benefits from reducing CT-related consequences relative to harms from the procedure need to be considered during decision making about implementing and participating in screening.

Different screening approaches are available with several considerations required related to their advantages and disadvantages. The relative priority between aims to prevent complications in individuals and to reduce transmission in the population may influence to whom, how often, and where screening if offered. Frequent and targeted screening of a specific proportion of the population may enable overall reduction of transmission in the larger population [50].Screening to reduce clinical complications in individuals may focus on opportunistic screening at visits to clinician offices or other health care sites including school-based health centers, STI clinics, pharmacies [51], or emergency departments [52]. Other detection strategies may focus on hard-to-reach individuals using outreach to non-health community settings such as gathering sites at colleges, bars, sex venues, or mobile vans [53-55]. Considerations for targeting individuals at increased risk of infection, based on sexual behaviors or group membership, include underreporting, possible stigmatization, practical considerations (e.g., addition of pre-screen to identify those at risk), and awareness that many cases may be missed. Conversely, screening the general/entire population that will on average have a lower prevalence of infection will increase rates of false positives and may lead to some unintended harm. The availability of non-invasive diagnostic tests (urine, self-swabs) may reduce the likelihood of people experiencing discomfort or embarrassment during the procedure and make screening easier to implement. However, the lower sensitivity for urine tests in females needs consideration [56]. Although at much lower prevalence than $\mathrm{CT}$, consideration of whether to also screen for NG arises because of the availability of laboratory tests that can evaluate both organisms from a single sample and test and because current combined first-line treatment for NG (regardless of CT presence) can in most uncomplicated cases also treat CT [57].

Since 2010, national guidance from the Public Health Agency of Canada has recommended screening for CT in at-risk groups of any age and in all sexually active females and males under 25 years of age and pregnant women [58]. The 24-year age limit aligns with the statistics used from 2004, in which the highest reported cases of CT were among those aged 15-24 years. The inclusion of males is due to their being a source for infections 
and reinfections of their female partners, for which the consequences were considered more clinically significant. Screening annually is recommended for those under 25 years old and for gay, bisexual, and other MSM and transgender populations; screening and repeat screening, of unclear frequency, is recommended for people $\geq 25$ with risk factors. Guidance also extends to case finding and partner notification as critical for controlling NG, but a specific definition (e.g., active seeking of signs and symptoms in at-risk individuals) or methods for case finding are not described. The current Canadian guidance was not based on a systematic review. Further, rates of CT have increased over time for those aged 2529 , and there are reports from screening trials completed after 2010 that would not have been considered by the guideline panel $[8,9,28,59,60]$.

Preferences for or against a screening strategy are influenced by the relative importance people place on the expected or experienced outcomes incurred [61-63]. Evidence on how people weigh the relevant outcomes is important to inform guideline panels when considering the balance of benefits and harms and determining whether this balance might vary across different individuals [64].

\section{Purpose of review}

To examine evidence on the effectiveness (impact of screening on critical/important benefits and harms) and comparative effectiveness of screening for CT and NG infections and on the relative importance people place on the relevant outcomes (patient preferences) from screening, to inform the Canadian Task Force on Preventive Health Care when making recommendations on screening to support primary health care providers in delivering preventive care. Existing reviews on screening effectiveness (e.g., $[19,65])$ were considered out-of-date with knowledge of at least one new trial [8] and had different eligibility criteria than the Task Force's. We are not aware of any existing reviews covering the full scope of the question on patient preferences. Several factors provided rationale for this review and its associated recommendations, as described in the additional files of the protocol [66].

\section{Methods}

The review was undertaken following a peer-reviewed protocol [66] and is reported following current standards for systematic reviews [67]. The methods are outlined briefly here, focusing on the eligibility criteria and any deviations or new methods developed after the protocol. Methods for the review on the relative importance placed on the outcomes from screening (values and preferences) align with those used by members of Grading of Recommendations Assessment, Development and Evaluation (GRADE) [62].

A working group of the Task Force, with input from four topic experts, developed the key questions (KQs) and inclusion/exclusion criteria for the review (Additional file 1). The Task Force and topic experts rated the outcomes according to methods of GRADE [64]. Outcomes with final ratings as critical (7-9 on 9-point scale) by Task Force consensus were the following potential benefits (with reductions in): transmission of CT and NG via reduced incidence or prevalence of the infections over time, cervicitis, PID, chronic pelvic pain in females, ectopic pregnancy, and infertility in females and males. Two harm-related outcomes were rated as important (4-6 on scale): serious adverse drug reactions and negative psychosocial impact of screening or diagnosis. The ratings of outcomes were not changed after findings from an outcome rating exercise and focus groups with a sample of sexually active individuals in Canada conducted by an independent group with expertise in knowledge translation from St. Michael's Hospital in Toronto, Ontario. Stakeholder organizations reviewed the KQs and inclusion/exclusion criteria $(n=14)$ and a draft version of this report $(n=15)$. All comments were taken into consideration, and no substantive changes were made to the conclusions.

\section{Key questions}

The key questions (KQs) of interest were as follows:

KQ1: What is the effectiveness of screening compared with no screening for chlamydia and/or gonorrhea in non-pregnant sexually active individuals?

KQ2: What is the comparative effectiveness of different screening approaches for chlamydia and/or gonorrhea in non-pregnant sexually active individuals? KQ3: What is the relative importance that people place on the potential outcomes from screening for chlamydia and/or gonorrhea?

\section{Eligibility criteria} Key questions 1 and 2

The population of interest for KQs 1 and 2 was nonpregnant sexually active individuals of any age, who were not seeking care for symptoms. We excluded studies focusing on pregnant persons, but not those that may have included individuals who were pregnant. Studies that included more than $25 \%$ of individuals seeking care for symptoms at baseline were excluded. We also excluded studies enrolling individuals already known to have recent $\mathrm{CT}$ and/or NG infections, except when capturing 
the outcomes of interest related to psychosocial harms of a diagnosis from undergoing screening.

Interventions of interest included any screening approach that included testing and management for individuals who tested positive. We excluded studies using point-of-care tests because these tests are not approved for use in Canada. We included studies on screening for $\mathrm{CT}$ and/or NG along with any other STI(s) because the outcomes of interest are attributed to CT and NG. The comparisons of interest were no screening (KQ1) or a screening approach differing from the intervention (KQ2) by the main variables of interest (Additional file 1 Table 1).

The outcomes of interest were those rated as critical or important for decision making by the Task Force, as described above. Infection transmission and infertility required at least 3 and 12 month's follow-up, respectively. Chronic pelvic pain was defined as being of at least 6 month's duration. Treatment rates in the study populations were considered as a proxy for transmission.

Randomized (RCTs) and non-randomized controlled clinical trials (CCTs), as well as retrospective and prospective controlled cohort studies, were included for all outcomes. As defined in the protocol, the decision to accept uncontrolled studies for the outcome of negative psychosocial impact was based on the lack of evidence from controlled studies. We did not have a minimum threshold for a study's risk of bias but considered the risk of bias when interpreting the findings. We included studies published in English or French, on or after 1996 aligning with the introduction of most relevant NAAT tests, and conducted in high or very high Human Development Index countries [68] to achieve a similar epidemiologic and healthcare context as Canada.

\section{Key question 3}

For assessing the relative importance of the outcomes, all participants could have had symptoms or a recent diagnosis of CT and/or NG. Participants may not have experienced screening or testing for CT or NG but could have experienced or been presented with information about the relevant clinical outcomes. Post hoc, we included studies where the participants (e.g., caregivers, clinical experts) were serving as a proxy for the eligible population. The exposures of interest were (i) experience with any screening program for CT and/or NG, (ii) experience with an infection or one of the critical outcome(s) of interest, or (iii) exposure to scenarios about the possible outcomes of screening. A comparator of no screening was not relevant because the focus was on the relative importance of the different possible outcomes. Unlike when assessing harms from screening or a diagnosis in KQ1, in KQ3 studies with data on harms, participants did not have to have experience with screening, there did not have to be data for comparison from before the intervention/diagnosis or with people without these experiences, and there needed to be a comparison with benefits. We also used qualitative findings for this question but not for KQ1. Outcomes/data of interest included (i) health-state utility values or other utility values, (ii) non-utility, quantitative information on relative importance of benefits versus harms, and (iii) qualitative information indicating the relative importance between benefits and harms. Any experimental, descriptive, or qualitative study design met inclusion criteria, including surveys, qualitative studies, stated and revealed preference studies, and studies measuring health-state utility weights (Additional file 1 Table 2). Criteria related to language, publication date, and country were the same as for KQs 1 and 2.

\section{Searching the literature and selecting studies}

Our research librarian conducted comprehensive, peerreviewed, searches in relevant bibliographic databases on June 5, 2018, with an update on January 24, 2020: Ovid Medline, Ovid Embase, Wiley Cochrane Library, CINA HL via EBSCOhost, and Ovid PsycINFO (searches in Additional File 7 in protocol [66]). The search was comprehensive for all KQs, with the exception of studies for KQ3 measuring health-state utility values for which we updated the search of an existing systematic review from 2013 to January 26, 2020 [32]. Additional sources of literature for all KQs were ClinicalTrials.gov (inception2018), meeting abstracts via the Conference Proceedings Citation Index-Science edition (Clarivate Analytics; 19962018), and reference lists of included studies and relevant systematic reviews. We also searched for reports of research using websites of several organizations: Centers for Disease Control and Prevention, BC Centre for Disease Control, College of Registered Nurses of British Columbia, International Union Against Sexually Transmitted Infections, Pan American Health Organization, Public Health Agency of Canada, and the World Health Organization. Independent review by two reviewers with consensus or third reviewer involvement was used for screening and final selection of studies.

\section{Data extraction and analysis}

One reviewer extracted data and another verified all data for accuracy and completeness. Study and population characteristics were extracted based on a priori variables (Additional file 1) and were tabulated. As described in Additional file 1, the definitions for some outcomes were refined after study selection but before analysis. In particular, for psychosocial harms, we received clinical input to determine which of many reported outcomes aligned with the outcome categories of interest. Further, for KQ3 when using utility values because of large variation 
in the duration of the different health states (e.g., PID typically has a much shorter duration than chronic pelvic pain), we multiplied the utility values by an estimated duration of effect using the range of durations applied in various cost-utility analyses [32]. This generated an estimated range of the quality-adjusted life year losses (QALY loss) for each state. Using these QALY loss estimates, we then determined a rank order of importance of the relevant outcomes and reported this in addition to the main outcome of the utility value for each health state. Assumptions relevant to this approach are described in Additional file 2.

We intended to assess risk status by participant reports of sexual behaviors and/or other factors increasing risk, but due to lack of reporting or use of risk factors for inclusion, we needed to rely on CT or NG baseline prevalence in the studies to categorize studies as enrolling populations, versus individuals, at general or high risk. Based on the baseline prevalence in the trials of general populations (4-6\%), consideration that Canadian statistics (of about 1-2.5\% CT) represent underreporting possibly by $70 \%$, and after input from the Task Force and content experts, greater than $7 \% \mathrm{CT}$ prevalence at baseline was used as the threshold for an increased risk study population.

When meta-analysis was possible and appropriate, due to similarity in populations, outcomes, and interventions, we used the DerSimonian Laird random effects model using Review Manager Version 5.3 (The Cochrane Collaboration, Copenhagen, Denmark). When results were not combined using meta-analysis due lack of common measurement (e.g., harms data), we used narrative descriptions of each study for our analysis and interpretation. We then compared and contrasted study findings by study methodology, populations, outcome presentations provided to participants (for KQ3), and analysis. With qualitative studies in KQ3 on the relative importance between harms and benefits when making decisions about screening, there was often numerical data from content analysis to use for the analysis, and in other cases, we used data on the frequency of comments/ quotes related to our critical outcomes and interpreted the strength of the preference based on the language in quotes and narratives from the authors.

For studies using cluster design but not appropriately accounting for this in their analysis, we adjusted the findings using an interclass correlation coefficient of 0.028 [69]. For dichotomous outcomes, we report relative risks (RR) or odds ratios (OR) between groups with corresponding 95\% confidence intervals (95\% CI). When ORs were used for the analysis, we calculated RR using the control event rate. We also calculated the absolute risk reduction and risk differences, based on GRADE guidance [70]. In addition to using the study control event rates (medians when multiple studies were in the analysis) for calculating absolute effects, we also made calculations to estimate-relying on natural history parameters (see Additional file 2)-assumed/illustrative effects for both general and high-risk (i.e., prevalence) populations for the PID outcome.

We had several population and intervention variables of interest for performing potential subgroup/stratified analysis for the outcomes where meta-analysis was performed and indicated heterogeneity (Additional file 1), but because of including few studies in all metaanalyses, no subgroup analyses were conducted. Several sensitivity analyses were conducted, based on risk of bias, study design, or our need to make assumptions during data analysis. If there had been at least eight studies of varying size in a meta-analysis, we would have analyzed for publication bias both visually using the funnel plot and quantitatively using Egger's test [71].

\section{Risk of bias assessments}

We used several methods and tools for assessing risk of bias, for RCTs and CCTs [72, 73], cohorts [74], surveys/ cross sectional studies [75], and qualitative studies [76]. We relied on recent guidance from GRADE for assessing risk of bias of studies in KQ3 measuring utilities and adapted the Newcastle-Ottawa tool for cohort studies [74], as described in Additional file 2. Risk of bias ratings for all studies contributing to each analysis were used during our assessments of the certainty of evidence.

\section{Assessing the certainty of the evidence on outcomes across the studies}

For KQs 1 and 2 on effectiveness, we did separate GRADE assessments for trials (starting at high certainty) and observational (starting at low certainty) study designs and relied on guidance from GRADE [64, 77-79]. For the KQ3 on patient preferences, we relied on GRADE guidance published after the protocol publication [61, 63]. We did not rely on RCTs for obtaining high certainty evidence for this $\mathrm{KQ}$ because causation from the intervention is not relevant to valuation of outcomes.

Our GRADE assessments were based on absolute rather than relative effects and considered thresholds for minimally important effects that were developed (see Additional file 2) for several outcomes: PID, 2.5 fewer or more cases per 1000 (e.g., reflecting a 25-32\% relative reduction in estimated $0.8-1 \%$ CT-related PID); ectopic pregnancy and infertility, 1 fewer or more per 1000; CT and NG transmission, 5 fewer or more per 1000 (10 fewer or more per 1000 was determined to be a moderate effect) when using prevalence data, and 20 more or fewer per 1000 when using treatment rates as a proxy for transmission. We did not base our assessments of 
precision on the null/statistical significance but rather the estimates of effects and the 95\% CIs in relation to the thresholds. Assessments and findings are presented narratively and using tables including GRADE Evidence Profiles and Summary of Findings tables.

\section{Interpretations}

We chose to use standard wording to describe the level of certainty of each finding. For findings of high, moderate, and low certainty evidence, we use "will," "probably/ likely," and "may/appears to," respectively, in our textual descriptions when discussing the results [80]. For very low certainty findings, we either use "may (make littleto-no difference/reduce/increase), but the evidence is very uncertain" or "the evidence is very uncertain," reflecting a continuum of our certainty (from a small amount to none) within this category [80].

\section{Results}

Our searches retrieved 16,458 unique citations, and after screening of abstracts (when available) or titles, 15,407 were excluded as irrelevant. After reviewing 1051 full texts, we included 41 studies $[8,9,12,28,59,60,81-115]$ with three additional associated publications [116-118] (Fig. 1). The 1007 studies excluded based on full text review are listed, with reason, in Additional file 3. Many studies reporting on harms from a CT or NG diagnosis were excluded because the diagnosis was not attributed to a screening intervention and/or more than $25 \%$ of participants reported symptoms before the testing. Further details on the studies are included in the below sections based on KQ and outcome.

\section{Effectiveness of screening versus no screening (key question 1)}

For KQ1, we included 14 studies that reported on potential benefits: 10 RCTs $[8,9,12,28,59,60,98,105,108$,

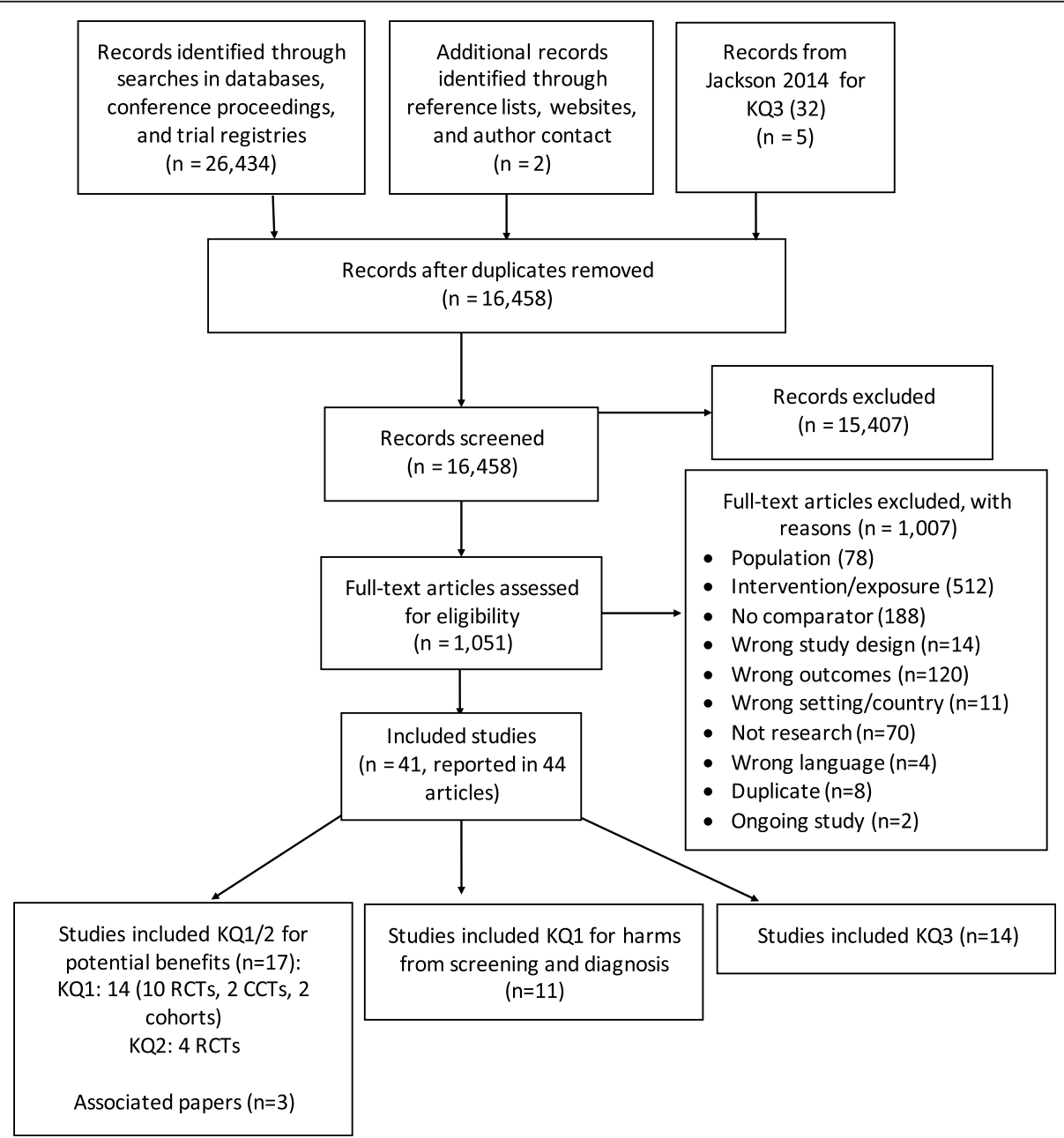

Fig. 1 Literature flow diagram for all key questions. *One RCT [109] was included for KQs 1 and 2, and another RCT [8] was included for KQ1 benefits and harms 
109], 2 CCTs [88, 89], and 2 retrospective cohorts [101, 111]. One RCT [8] and 10 uncontrolled cohort studies [81, 86, 92-95, 97, 100, 104, 114] were included for harms of the screening process or a diagnosis of CT from a screening program.

\section{Benefits}

Study characteristics Table 1 and Additional file 4 include the characteristics of studies addressing the benefits from screening versus no screening. Ratings of risk of bias by study are included in Table 1, Fig. 2, and Additional file 5 . We did not locate any trials where the comparator was no screening; all trials had usual care controls which were described as including some form of ad hoc screening, regardless of further contamination bias from lack of participant blinding. We included these in a post hoc manner as indirectly relevant to KQ1. Although there was a small amount of overlap, studies naturally formed groups based on whether they focused on the more clinical (individual) outcomes or on transmission (population). None of the studies only screened for NG. All studies employed a universal approach with all enrolled participants offered or undertaking the screening; we did not locate any studies employing a risk-based strategy whereby outcomes in an entire general population were assessed based on only screening those deemed to be at higher risk.

Five RCTs [8, 28, 59, 105, 108], one CCT [88], and two cohorts $[101,111]$ provided data for one or more of the clinical outcomes of PID, ectopic pregnancy, or infertility in females from CT screening. No study reported on cervicitis, chronic pelvic pain in females, or infertility in males. The three trials by Hocking et al. [8], Andersen et al. [59], and Scholes et al. [108] used an intention-to-screen design, whereby universal screening was offered and results were captured in the entire population regardless of screening attendance. Hocking and Andersen both enrolled general populations in healthcare clinics or via population-based registers, respectively, meeting their age criteria. Other facets of the intervention in Hocking included provider reminders, education, payments and feedback, and patient recall systems. Scholes enrolled females recruited by telephone with a questionnaire to enroll those with an increased risk for $\mathrm{CT}$ and who were willing to set up a primary care clinic appointment to have the clinician collect a cervical swab [108]. This trial was considered to enroll a select population interested in screening. Screening rates in Hocking and Andersen were fairly low (24-29\%), whereas those in Scholes were high [64\%]. The females in all three RCTs were considered to be at general risk ( $\leq 7 \% \mathrm{CT}$ at baseline), despite the attempt in Scholes to obtain a high-risk sample. Hocking reported on PID diagnosed in clinics and hospitals at 3-year follow-up, Andersen reported on PID at 1-year follow-up and infertility and ectopic pregnancies after 9 years, and Scholes reported on PID at 1 year. Few data on risk factors were reported; in Hocking, 32\% reported two or more sexual partners in the past 12 months, and in Andersen, the participant characteristics only included marital (e.g., $20 \%$ were married) and employment status.

The RCTs by Ostergaard et al. and Oakeshott et al. $[28,105]$, the CCT by Clark et al. [88], and the two cohort studies by Low et al. and Sufrin et al. [101, 111] were considered to use acceptors of screening design rather than an intention-to-screen approach because of only enrolling females submitting a sample or having very high uptake (93\%) [105] of the offer of a test in the screening group. All three of the trials used outreach recruitment in non-healthcare settings within high schools [105], universities [28], or military training centers [88]. Ostergaard and Oakeshott both reported on PID at 1year follow-up. Ostergaard did not account in their analysis for clustering, so we adjusted their findings. The CCT by Clark compared rates of PID, ectopic pregnancy, and infertility at mean follow-up duration of about 1.5 years. On average, the females in Ostergaard and Oakeshott were at general risk, while those in Clark had an increased risk ( $9 \% \mathrm{CT}$ at baseline). The cohort study by Low examined rates of PID, ectopic pregnancy, and infertility in females over 10 years, linking data from a population register to hospital discharge codes in a Swedish county where opportunistic screening had been routinely undertaken [101]. Sufrin investigated rates of PID development 3 months after insertion of an intrauterine device in primary care, based on screening status in the 1 year prior to the insertion [111].

The trials reporting on transmission using estimated population prevalence $(4 \mathrm{RCTs}[8,9,12,60])$ or participant positivity at follow-up (1 CCT [89]) employed cluster designs with intention-to-screen approaches as appropriate for this outcome. The RCTs by Hocking et al. [8], van den Broek et al. [9], and Hodgins et al. [12] were similar in that they enrolled general-risk populations and offered low-intensity interventions with annual screening tests for 1 to 3 years. Screening rates were quite low (16-31\%) across these trials. Two trials, by Garcia and Cohen, focused on high-risk populations ( $>11 \% \mathrm{CT}$ at baseline) with more intensive CT and NG screening programs using outreach programs in communities for female sex workers (FSWs) in Garcia and high schools in Cohen. In the trial by Garcia, other interventions within the general populations of these clusters involved multifaceted syndromic management in the general population and clients of FSWs, condom promotion with motivational interviewing and free condoms, and peer education. We adjusted for the effects of clustering in trials by Hodgins and Cohen. 


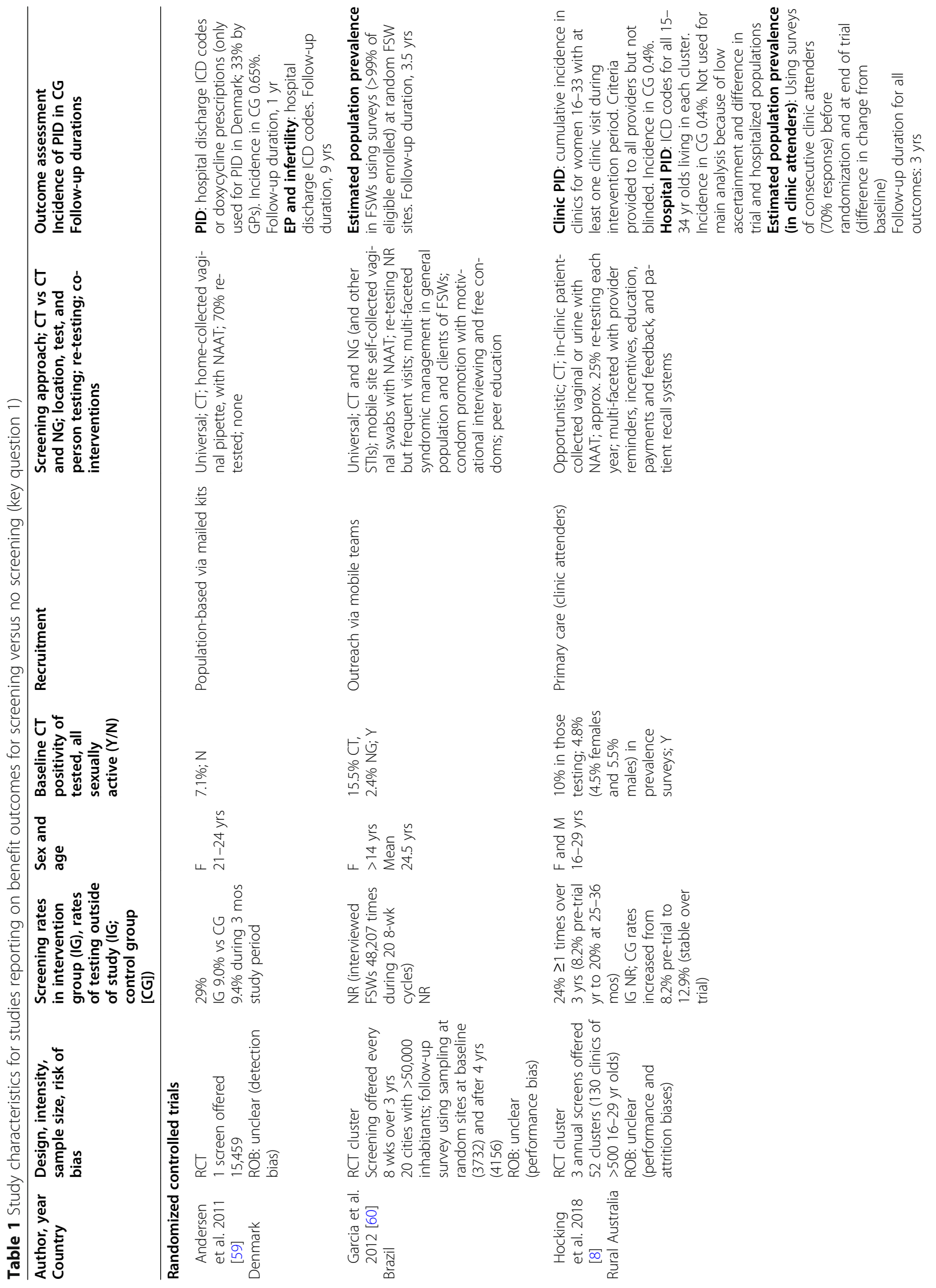




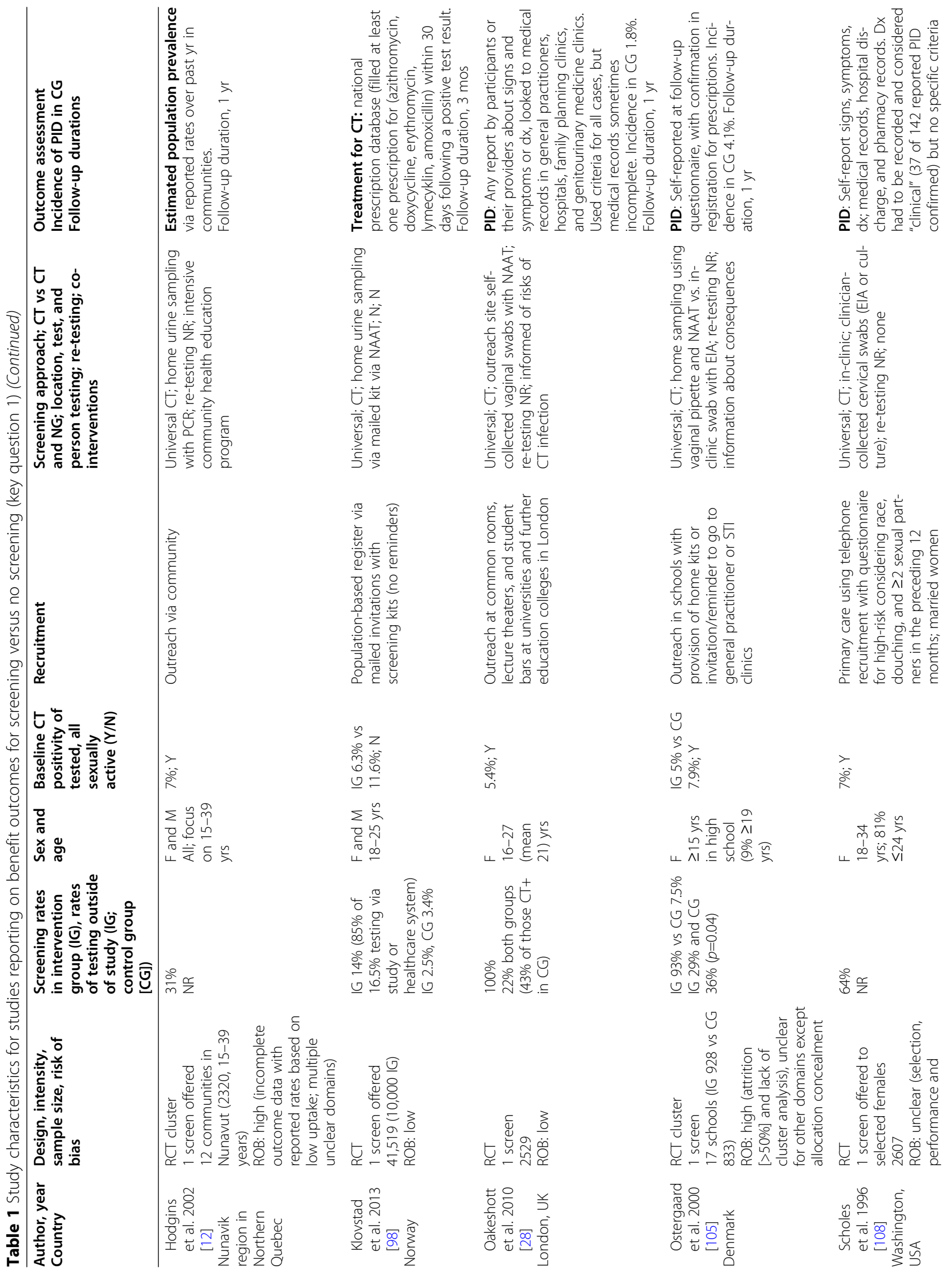




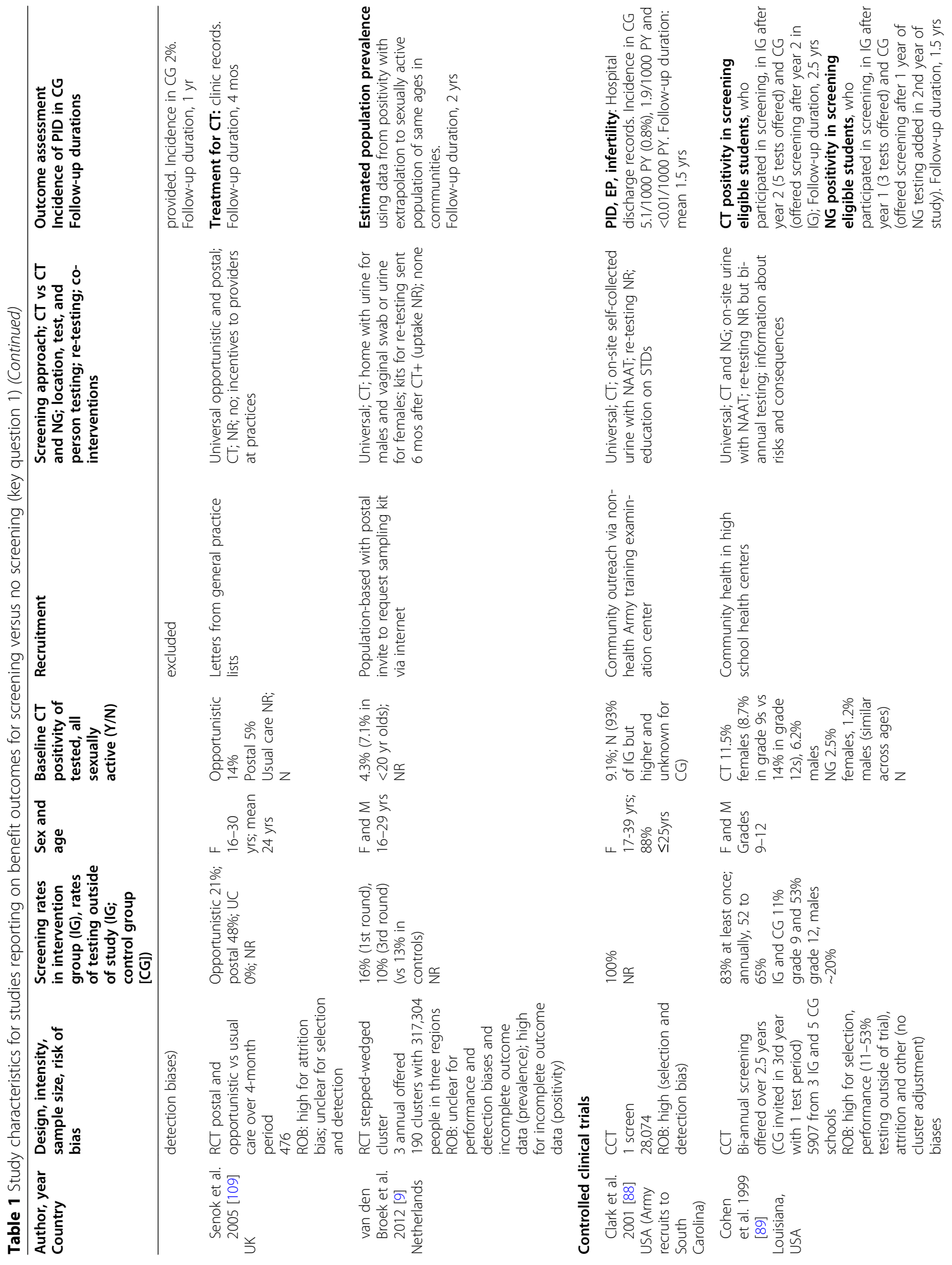




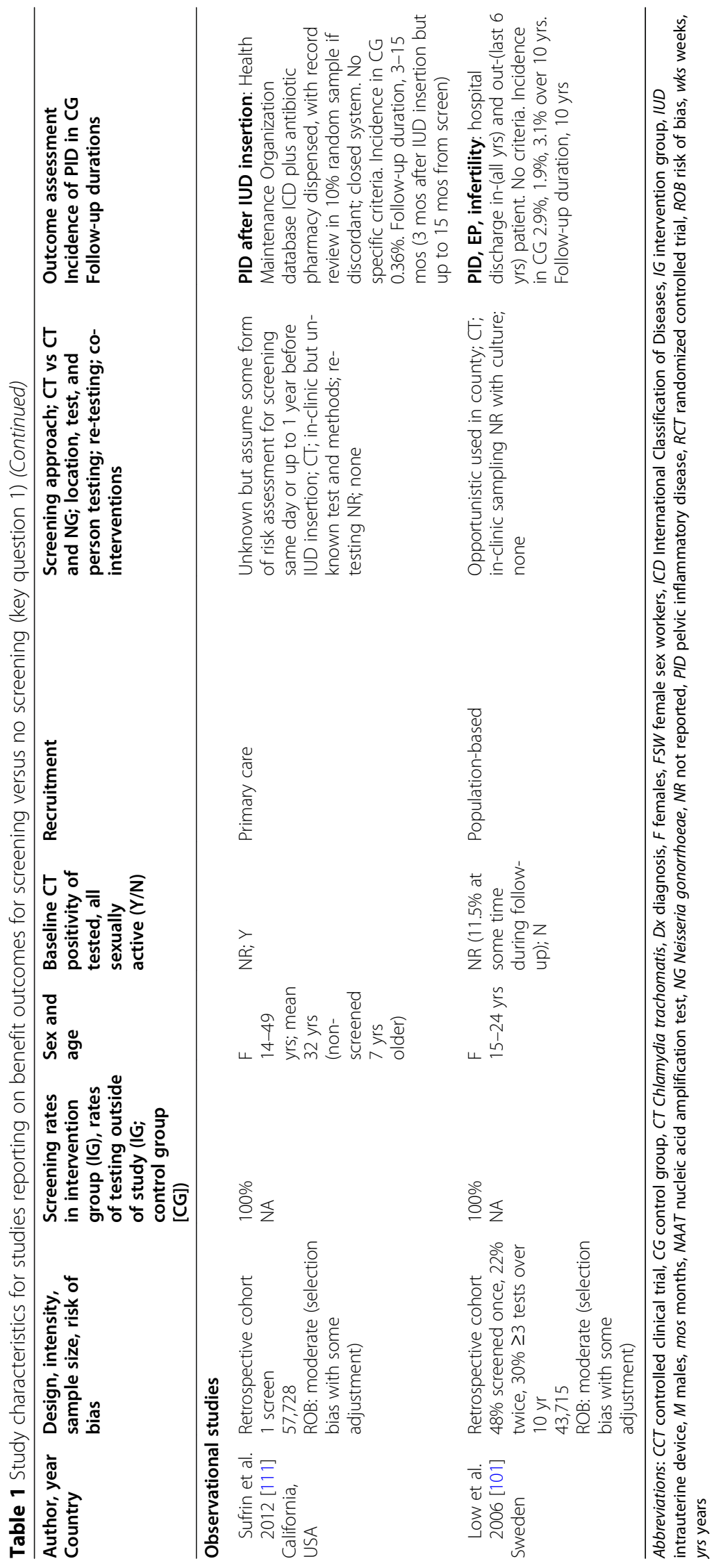




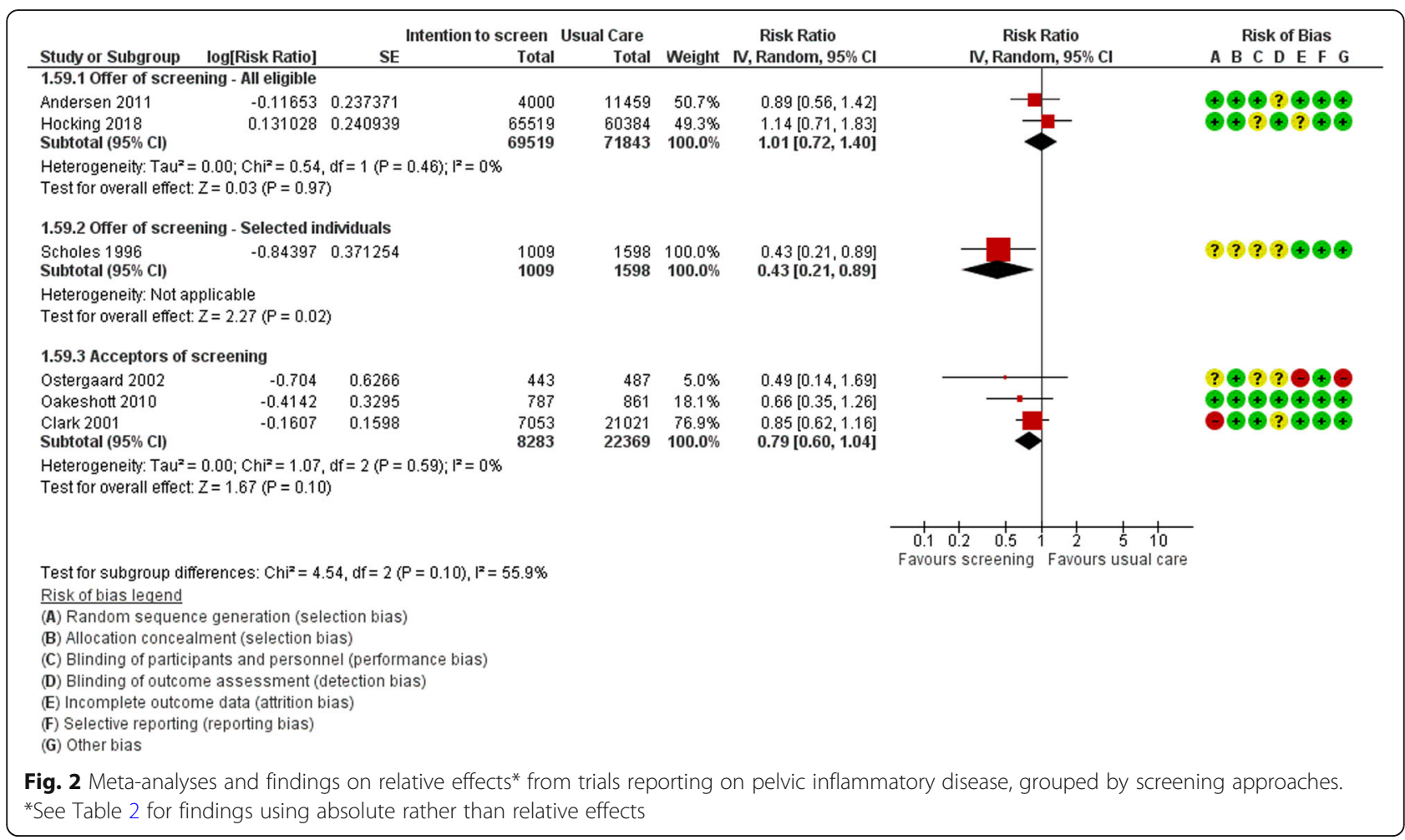

Two RCTs reported on treatment rates in populations offered a screening test/visit through population-based home sampling using mailed kits [98] or either on-site or via mailed kits from a general practice clinic [109]. Screening rates were between 14 and $48 \%$, with higher rates from invitations from health clinics compared with a population-based registry.

Pelvic inflammatory disease Figure 2 shows the study findings and analyses of trial data for PID. Table 2 summarizes the main findings for the KQ1 benefit outcomes, and Additional file 6 contains all of the review's GRADE Evidence Profiles and Summary of Findings Tables including explanations for all ratings. We did not pool results across all six trials reporting on PID because of substantial differences between screening approaches and settings.

Offering screening for CT universally, via opportunistic [8] or population-based [59] approaches achieving low screening rates, to females 16-29 years old may make little-to-no difference in risk of all-cause PID over 1- to 3-year follow-up when using assumed risks in general or high-prevalence populations. The evidence is very uncertain due to imprecision and serious indirectness from the following: use of comparison groups receiving some screening, reliance on recruitment from population registers in one trial which may not reflect primary care, and lack of complete outcome ascertainment $[8,59]$. When applying an assumed population risk from the median control event rate in the studies, the evidence of this trivial effect is of higher certainty (low-to-moderate rather than very low) because of no concerns about imprecision when event rates are low (PID in $0.4-0.65 \%$ of the study control group vs. $2.7 \%$ in estimates for the general population based on natural history of CT). The data from the Hocking RCT for this analysis was based on clinic records for all patients attending the clinics during the trial period and accounted for most (approximately $80 \%$ ) of the PID cases in the trial. Using hospital data for all people within the eligible age range residing in the clusters captured about $20 \%$ of the PID cases (if assuming hospital cases were not recorded in clinic charts) and indicated that there may be a reduction in PID hospitalizations (general-risk estimate 10.8 fewer per 1000 [16.2 to 0 fewer]; high-risk estimate 18.8 fewer per 1000 [28.2 to 0 fewer]), but the evidence is very uncertain.

The RCT by Scholes et al. [108] indicated that there appears to be a reduction in PID over 1-year follow-up for general-risk females showing interest in screening. Three other trials indicated that screening may reduce the risk for PID over 1 year for females 15-29 years of age who accept and undergo one CT screen in outreach settings $[28,88,105]$. When assuming a high-risk population for the effects from these studies of either selected individuals or screening acceptors, the magnitude of effects may be greater, but there is more uncertainty because of reliance for these calculations on the RR and baseline estimates of PID that were generated from data 


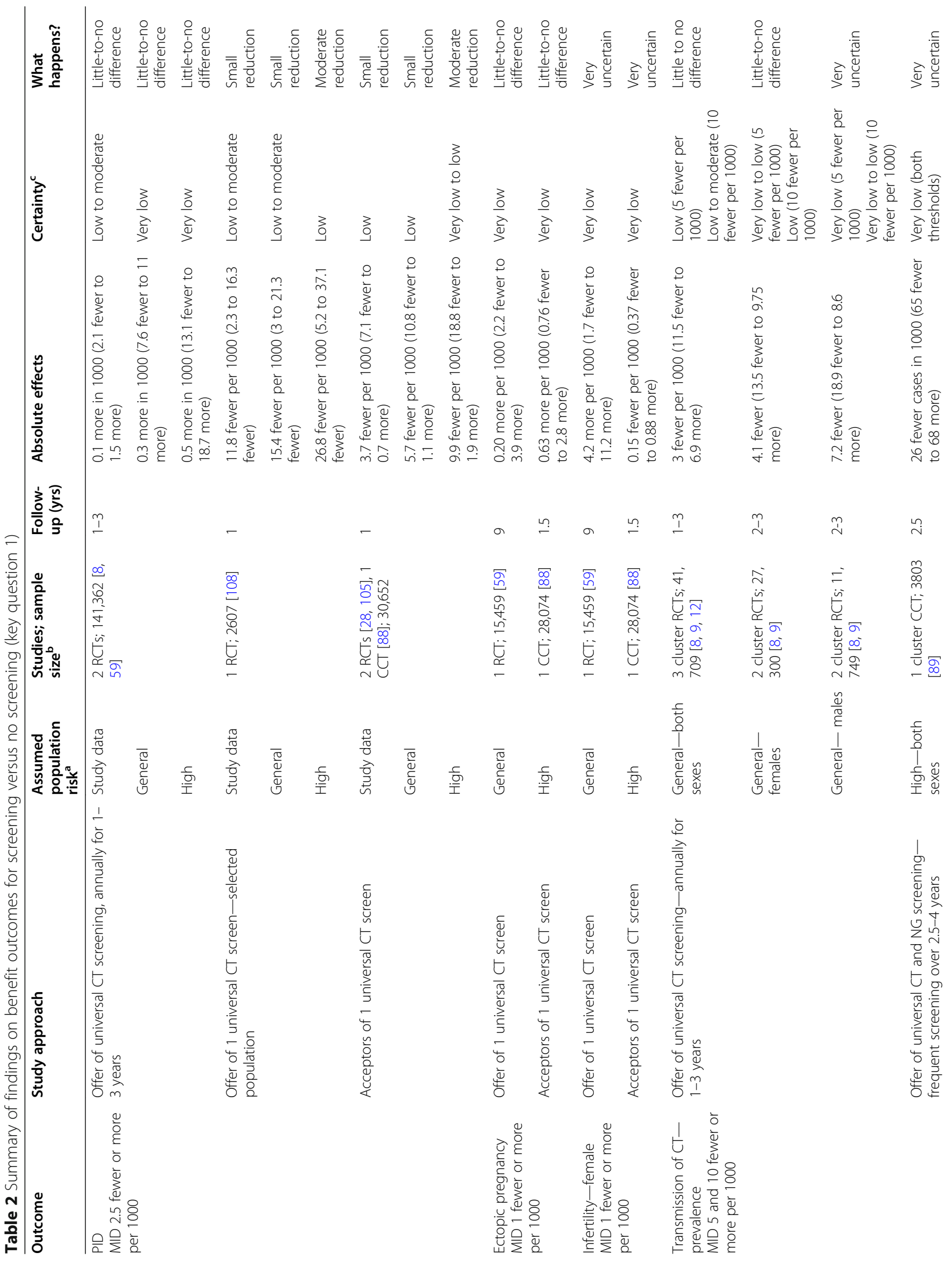




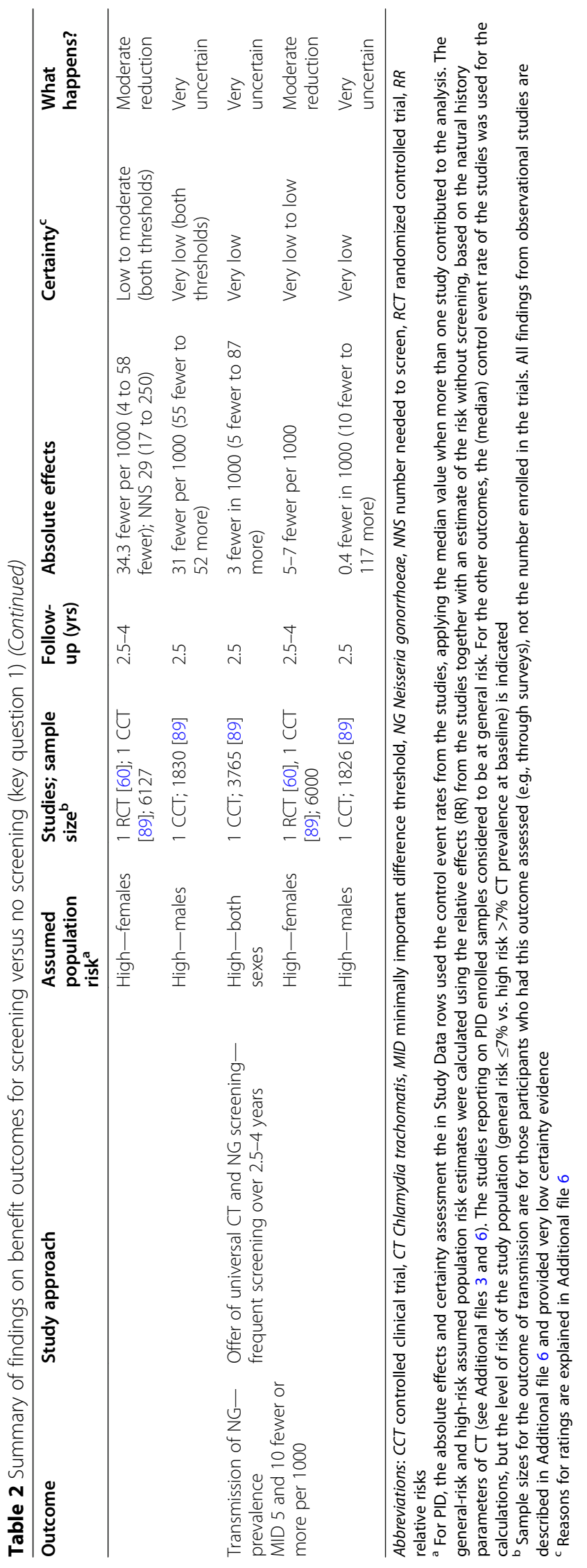


in general-risk populations. Sensitivity analyses removing the CCT by Clark did not impact findings. We used rates from patients with data at follow-up in Ostergaard because of large attrition rates in this trial; sensitivity analysis using data from all females randomized (intentionto-treat analysis) did not impact findings. Overall, the findings from these four trials are considered indirect to the main interests of the Task Force, to determine what would occur by offering primary-care based screening to unselected populations.

The evidence from observational studies $[101,111]$ is very uncertain about the effects of being screened for $\mathrm{CT}$ on PID, due to some concerns about risk of bias, serious inconsistency, and some indirectness.

Ectopic pregnancy Offering a single CT screen to general-risk females, aged 21 to 24 years, may make little-to-no difference in rates of ectopic pregnancy over 9 years, but the evidence is very uncertain from reliance on a single RCT with concerns about indirectness from only using hospital diagnoses and imprecision [59]. Findings are similar from one CCT with 1.5 years follow-up for high-risk females accepting a screen [88]. The evidence from one cohort study [101] is very uncertain.

Infertility The evidence is very uncertain about the effects on infertility from offering (1 RCT [59]) or for acceptors of CT screening (1 CCT [88], 1 cohort [101]). There was inconsistency between studies and serious concerns about indirectness from use of hospital data and the use of usual care comparisons. Data from the RCT was also imprecise, and that from the CCT had additional indirectness based on short-term follow-up (1.5 years) and use of an outreach setting.

Transmission of CT Based on estimated population prevalence rates, offering screening to both sexes, 15-29 years old at general-risk for CT, annually for 1 to 3 years may make little-to-no difference $(<5$ fewer infections per 1000) in the transmission of CT when considering both sexes together [8, 9, 12]. Sensitivity analysis removing the trial [12] where we had to assume similar intervention and control group sample sizes and that reported rates of infections in the community were applicable to the population-based sample did not affect findings. There is more certainty (moderate-to-low compared with low) of the trivial effect when applying the higher threshold of 10 fewer infections per 1000 screened. Findings were similar for transmission in general-risk females only, except for having very low certainty because of more imprecision. The evidence for males is very uncertain. The one trial [8] that performed subgroup analysis based on age found no interaction effects $(p=0.75)$. Findings from studies reporting on treatment rates as a proxy for transmission are similar, with low certainty that offering a single CT screen will make little-to-no difference in transmission.

Frequent offers of screening for CT and NG in highrisk females (e.g., CT prevalence 11-15\%), 15-29 years old, appears to reduce CT prevalence to a moderate extent $(>10$ fewer per 1000) in these females $[60,89]$. The evidence is of moderate-to-low certainty due to some concern about risk of bias and serious indirectness from the outreach approaches, use of usual care comparisons having some screening, and co-interventions provided in the Garcia trial. The evidence about screening high-risk populations for $\mathrm{CT}$ and NG on transmission of CT when considering prevalence in both sexes ( 1 CCT; $n=5907$ ) and in males only (1 CTT; $n=1830$ ) is very uncertain [89].

Transmission of NG Frequent offers of screening for CT and NG in high-risk females (e.g., NG prevalence $2.5 \%)$ may reduce NG transmission in these females to a moderate extent ( $>5$ fewer per 1000) [60, 89]. The evidence is very uncertain about the effects on transmission of NG across both sexes or in males, from the CCT where screening for $\mathrm{CT}$ and NG was offered to both sexes at high-risk [89].

\section{Harms}

Study characteristics The Hocking RCT reported on serious adverse events from treatment through passive surveillance methods. Of the 10 uncontrolled cohort studies [81, 86, 92-95, 97, 100, 104, 114], seven reported on harms from undertaking screening and seven reported on harms from a positive diagnosis of CT after screening (Additional file 4). Four of the seven studies on screening harms only enrolled CT-negative individuals, not also those with infections but unaware of the results, such that the effects in the entire population eligible for screening may be different. Five studies enrolled about $60 \%$ females, four enrolled only females, and one did not report the sex distribution. Half of the studies enrolled what was considered a high-risk sample, either because of $\geq 7 \%$ prevalence of CT and/or a moderate or high proportion of participants reporting risk behaviors such as multiple sexual partners or previous STIs. None reported on the number identifying with groups disproportionally affected by social or other factors (e.g., FSWs, MSM, injection drug users). Mean age across studies ranged between 18 and 25 years. Two studies assessed harms in a longitudinal manner: Gottlieb et al. [94] at the testing visit and 4-6 weeks later, and Campbell et al. [86] before the invitation, during testing, and after receiving the negative results. Other studies relied on comparisons between CT positive and negative individuals. Studies were mostly lacking in long-term follow-up, with 
the exception of one study [104] reporting on partner break-up or violence at 1 year after diagnosis. Two studies examined harms from screening using outreach approaches [92, 100], one focused on a population-based register program [95], and the remaining seven were based on screening in primary care. Details for risk of bias by study and outcome are included in Additional file 5. Ratings of low or unclear risk of bias were given to all outcomes with the exception of data on general anxiety from a CT diagnosis in one study [81] that was at high risk due to lack of comparison with individuals without $\mathrm{CT}$ and inadequate data and follow-up duration.

Detailed findings, analyses, and reasons for certainty ratings for the harm outcomes are included in Additional files 4 and 6 .

Serious adverse events from treatment during a screening intervention The effects from screening on serious adverse events from treatment are very uncertain (1 RCT with no reports of events in 4574 receiving a CT diagnosis), due to serious concerns about risk of bias from lack of active harm surveillance and very serious concerns about imprecision due to the small sample for this very rare event [8].

Anxiety from screening Over the short-term, screening for CT may make little-to-no difference in general anxiety ( 2 studies, $n=2139$; low certainty) $[86,94]$ or anxiety about one's sexual aspects of life ( 2 studies, $n=$ 1937; low certainty for high-risk and very low certainty for general-risk individuals) [94, 97]. It may cause a small-to-moderate (50 to 400 per 1000) number of individuals to feel some degree of anxiety about their or their partner's infertility ( 2 studies, $n=450$; very low certainty), although findings were inconsistent and indirect $[95,97]$. Screening may make a small-to-moderate [10-46\%] number of people feel some concern or anxiety about CT (based in single items on questionnaires) (2 studies, $n=2307$; very low certainty); this evidence is uncertain, particularly for men and those without risk factors for CT. Feelings of concern and worry about CT may persist after receiving a negative result.

Shame/stigma from screening Over the short-term, screening for CT may make little-to-no difference in stigma manifested as low levels of overall self-esteem (2 studies, $n=1990$, low certainty) [86, 94]. One or more feelings related to stigmatization (mainly related to embarrassment and disapproval by one's social environment) may be experienced by a small-to-moderate (60 to 300 per 1000) number of individuals ( 5 studies, $n=$ 1823 , low certainty) $[92,95,97,100,114]$, although the severity of these symptoms are unknown.
Relationship distress from screening No studies reported on partner violence from screening for CT. In high-risk individuals, there may be little-to-no effect on relationship break-up as a direct consequence of undergoing screening ( 2 studies, $n=445$, low certainty) [94, 97]. Findings on the effects from CT screening on general relationship distress are very uncertain but suggest that responses from partners about screening may not be very negative and may be better than anticipated ( 2 studies, $n=1000$; very low certainty) $[97,114]$.

All studies reporting on psychosocial harms from screening enrolled individuals undergoing screening, who may not represent all individuals eligible to be offered a screening test. The data may therefore overestimate what will happen in the overall population eligible for a screening intervention.

Anxiety from a diagnosis A CT diagnosis may make little-to-no difference in symptoms of general anxiety (2 studies, $n=277$, very low certainty) $[81,86]$. A moderate-tolarge (400-600 per 1000) number of individuals (mainly females) diagnosed may feel some degree of anxiety about infertility (6 studies, $n=428$, low certainty) $[81,93-95,97$, $114]$, and a small-to-moderate number [100-300 per 1000] may feel anxious about one's sexual aspects of life (3 studies, $n=359$, very low certainty) [81, 94, 97]. Receiving a diagnosis of CT may cause one or more symptoms related to anxiety for a moderate-to-large (40-80\%) proportion of people ( 3 studies, $n=292$, very low certainty), but the evidence is uncertain and duration of effects unknown.

Shame/stigma from a diagnosis A CT diagnosis may make little-to-no difference for stigma manifested as low self-esteem (1 study, $n=149$, very low certainty) [94] but may lead to one or more stigma-related symptoms (e.g., feeling dirty, shame, embarrassment) for a moderate number (200-500 per 1000) of those diagnosed (6 studies, $n=506$, low certainty) $[81,93-95,97,114]$.

Relationship distress from a diagnosis The effects on relationship violence from a diagnosis of $\mathrm{CT}$ are uncertain (1 study, $n=298$, very low certainty) [104], but a diagnosis may lead to relationship break-up for a small proportion (about $5-10 \%$ ) of people in high-prevalence populations (4 studies, $n=994$, low certainty) $[81,94,97$, 104]. A CT diagnosis may cause some relationship distress for a small-to-moderate [100-500 per 1000] number of those diagnosed ( 5 studies, $n=553$, low certainty) $[81,94,95,97,114]$.

The proportion of people within an entire screeningeligible population experiencing the harms from a diagnosis will be substantially lower $(<2$ to $5 \%)$. 


\section{Comparative effectiveness of different screening} strategies (key question 2)

For KQ2, we included four RCTs that compared home versus clinic sampling for screening [90, 106, 109, 115]. Study characteristic tables are in Additional file 4, and risk of bias assessment is in Additional file 5. Detailed findings, analyses, and reasons for certainty ratings for these outcomes are included in Additional file 6.

Study characteristics One small RCT $(n=205)$ measured incidence of CT and NG in a high-risk (17\% CT) population of females after treating cases at baseline and then offering three screens over 18 months, in an outreach setting with provision of home testing kits (via mail or pick-up) or an invitation for clinic testing [90]. Three RCTs measured treatment rates in general-risk populations after various forms of recruitment: outreach via community promotion and websites [115], outreach via health clinic and community promotion [106], and postal invitations from general practice clinics [109]. All compared offers of screening at home (with mailed samples) versus screening in a primary care clinic. One of these three RCTs offered screening for CT and NG in both sexes [106], another offered screening for CT and NG in males, and another screened for CT in females [109]. Although screening was conducted at home in the intervention arms, participants had to attend clinics for treatment. All RCTs had unclear risk of bias, due to possible selection [90, 109], performance [90, 106, 109, 115], and detection biases $[106,109]$.

Transmission of CT and NG The evidence on the effects on transmission of $\mathrm{CT}$ and NG from incidence rates after moderate-intensity screening using home versus clinic sampling is very uncertain ( $1 \mathrm{RCT}, n=205$, very low certainty) [90]. Findings for treatment rates of CT or NG across both sexes (1 RCT; $n=2063 ; 1.9$ more treated per 1000 [ 1.7 less to 16.3 more]) indicated that home versus clinic sampling may make little to no difference in transmission of these infections, but the evidence is uncertain [115]. The effects on transmission of CT and NG in males are very uncertain ( $1 \mathrm{RCT}, n=200$ ) [106], as are the effects for transmission of CT in females ( 1 study, $n=260$ ) [109]. In these studies, the rates of screening were higher for home (38-72\%) versus clinic (19-48\%) sampling.

\section{Patient values and preferences: relative importance of outcomes (key question 3)}

Detailed study characteristics, risk of bias assessments, findings, analyses, and reasons for certainty ratings for this KQ3 are included in Additional files 4, 5 and 6. Table 3 summarizes the findings.
Study characteristics Four studies measured utilities for the health states of interest [96, 99, 110, 113]. Two groups of authors [110,113] directly measured utilities for PID (treated as both in- and out-patients), ectopic pregnancy, infertility, and chronic pelvic pain, using both time trade-off (TTO) and visual analog scale (VAS) instruments and similar clinical scenarios about the outcomes' symptoms, treatment options, complication risks (e.g., small chance of infertility from PID), and functional limitations. Smith et al. recruited 206 females (mean age 29 years) with and without a history of PID [110], whereas Trent et al. recruited adolescents (12-19 years) and their caregivers $(n=255)$, most not experienced with any outcome, from medical and school health clinics [113]. Kupperman et al. used a TTO to directly measure the utility of chronic pelvic pain in females seeking care for noncancerous pelvic problems $(n=272)$ [99]. A committee of the Institute of Medicine (IOM) studying priorities for vaccine development used topic expert input to indirectly measure utilities, by developing scenarios using the components of the Health Utilities Index Mark 2 tool, for several health conditions, including PID (out- and in-patient), cervicitis, chronic pelvic pain, ectopic pregnancy, and infertility [96]. The utilities were calculated using weighting from preferences of the general population in the USA. The main concerns with risk of bias across studies and outcomes were for (i) ectopic pregnancy in three studies [96, 110, 113] where the severity of the condition was thought to be underrepresented in the scenarios, (ii) PID in two studies [110, 113] from concerns about using TTO methods for temporary health states (i.e., the method assumes death follows the health state which is unrealistic for temporary states [119], and (iii) for all outcomes in the study by the IOM [96] from the use of experts rather than patients and from lack of reporting any measurement of variance in the findings.

Ten studies provided non-utility information on the relative importance of benefits and harms. Seven studies enrolled populations mainly considering rather than undertaking screening [82-85, 87, 107, 112]. Various settings were used for recruitment, including general practitioners' offices [82], universities or vocational colleges [83-85], an emergency department [107], and STI or community health clinics $[87,112]$. Five studies enrolled both sexes [83-85, 107, 112], aged between 16-29 years (one included adolescents 14-21 years old [107]), and four focused on high-risk populations $[84,85,87$, 107]. Six studies ( $n=23$ to 192) [82-84, 87, 107, 112] used semi-structured or open-ended questionnaires that focused on or included questions on beliefs about benefits and harms of screening, reasons for screening/factors that influenced decision making, and/or anticipations about screening. All studies analyzed their data using 
Table 3 Summary of findings on patient preferences (key question 3)

\begin{tabular}{|c|c|c|c|c|}
\hline Study designs & $\begin{array}{l}\text { Outcome } \\
\text { Studies; sample } \\
\text { size }\end{array}$ & Findings & $\begin{array}{l}\text { Certainty } \\
\text { of the } \\
\text { evidence }^{a}\end{array}$ & What does the evidence say? \\
\hline \multirow[t]{6}{*}{$\begin{array}{l}\text { Preference-based using } \\
\text { direct }(n=3) \text { and indirect } \\
(n=1) \text { methods to derive } \\
\text { health-state utilities }\end{array}$} & $\begin{array}{l}\text { Infertility HSUV } \\
3 ; 461[96,110,113]\end{array}$ & $\begin{array}{l}\text { TTO range } 0.76-0.91 \text { (SD 0.25-0.34); VAS } \\
\text { range } 0.53-0.68 \text { (SD 0.24-0.29); indirect } \\
0.82 \\
\text { Best estimate of utility value }=0.80 \\
\text { (range } 0.76-0.91 \text { ) }\end{array}$ & Moderate & \multirow[t]{5}{*}{$\begin{array}{l}\text { Based on utility values, the potential } \\
\text { benefits from screening are probably of } \\
\text { similar importance to people. }\end{array}$} \\
\hline & $\begin{array}{l}\text { Chronic pelvic pain } \\
\text { HSUV } \\
4 ; 733[96,99,110 \\
113]\end{array}$ & $\begin{array}{l}\text { TTO range } 0.69-0.85 \text { (SD 0.29-0.38); VAS } \\
\text { range } 0.45-0.61 \text { (SD 0.29-0.38); indirect } \\
0.60 \\
\text { Best estimate }=0.76 \text { (range } 0.69-0.85 \text { ) }\end{array}$ & Moderate & \\
\hline & $\begin{array}{l}\text { Ectopic pregnancy } \\
\text { HSUV } \\
3 ; 461[96,110,113]\end{array}$ & $\begin{array}{l}\text { TTO range } 0.79-0.91 \text { (SD 0.26-034); VAS } \\
\text { range } 0.55-0.73 \text { (SD } 0.21-0.25 \text { ); indirect: } \\
\text { out-patient } 0.58 \text { vs in-patient } 0.23 \text { with re- } \\
\text { cuperation } 0.60 \text { (added to PID health } \\
\text { state) } \\
\text { Best estimate }=0.83 \text { (range } 0.79-0.91 \text { ) }\end{array}$ & $\begin{array}{l}\text { Low to } \\
\text { moderate }\end{array}$ & \\
\hline & $\begin{array}{l}\text { PID HSUV } \\
3 ; 461[96,110,113]\end{array}$ & $\begin{array}{l}\text { PID out-patient: TTO range } 0.82-0.90 \text { (SD } \\
0.22-0.33 \text { ); VAS range } 0.62-0.76 \text { (SD 0.17- } \\
0.24 \text { ); indirect } 0.63 \\
\text { PID in-patient: TTO range } 0.82-0.88 \text { (SD } \\
0.27-0.36 \text { ); VAS range } 0.60-0.74 \text { (SD 0.20- } \\
0.25 \text { ); indirect IPNS } 0.57 \text { vs IPS } 0.46 \text { with } \\
\text { OPAIP } 0.83 \\
\text { Best estimate (majority treated as } \\
\text { outpatient) }=0.86 \text { (range } 0.82-0.90 \text { ) }\end{array}$ & $\begin{array}{l}\text { Low to } \\
\text { moderate }\end{array}$ & \\
\hline & $\begin{array}{l}\text { Cervicitis HSUV } \\
1 ; \text { NR [96] }\end{array}$ & $\begin{array}{l}\text { Indirect methods } 0.90 \text { (no measure of } \\
\text { variance) }\end{array}$ & $\begin{array}{l}\text { Low to } \\
\text { moderate }\end{array}$ & \\
\hline & $\begin{array}{l}\text { Rank order of } \\
\text { outcomes based on } \\
\text { QALY loss } \\
4 ; 733[96,99,110 \\
113]\end{array}$ & $\begin{array}{l}\text { Infertility > chronic pelvic pain >> } \\
\text { ectopic pregnancy = PID = cervicitis } \\
\text { Based on range of QALY losses ( }(1-\text { best } \\
\text { estimate of utility }) \times \text { duration in years) for } \\
\text { each health state: Infertility }(0.20 \times 10-30\end{array}$ & $\begin{array}{l}\text { Low to } \\
\text { moderate }\end{array}$ & $\begin{array}{l}\text { Infertility and chronic pelvic pain may be } \\
\text { considerably more important to females } \\
\text { than ectopic pregnancy, PID, and } \\
\text { cervicitis. }\end{array}$ \\
\hline
\end{tabular}

Survey $(n=1)$ and qualitative studies $(n=9)$ providing non-utility data
Relative importance of benefits vs harms Patients mainly considering rather than undergoing $C$ and NG screening 777 (7 studies)
Relative importance of benefits vs harms Patients who have undergone $\mathrm{CT}$ screening 77 (3 studies) each health state: Infertility $(0.20 \times 10-30$ years) $=2-6$ QALY loss $>$ chronic pelvic pain $(0.24 \times 5-10$ years $=1.2-2.4$ QALY loss) >> ectopic pregnancy (0.17 for 4 weeks $=0.013$ QALY loss $)=$ cervicitis $(0.10$ $\times 4$ weeks $=0.008$ QALY loss $)=$ PID $(0.14$ $\times 10-12$ days $=0.004$ QALY loss)

Two studies of general-risk populations found that harms from stigma of a diagnosis and (less so) anxiety from testing may outweigh the potential benefits on their reproductive health (unspecified outcomes) and transmission [82, 83]. One study's findings indicated that a fine balance may exist between a large potentia for reduced transmission and several harms, from stigma from testing, anxiety about $C T$, and relationship distress [84].

The remaining four studies suggested that the potential benefits from reduced transmission and (less so) improved future reproductive health will outweigh the harms from anxiety and stigma when making decisions about screening $[85,87$, $107,112]$. The relative importance placed on benefits may be higher for women.

The potential benefits for reducing infertility and/or transmission may outweigh any (transient and mild) harms from anxiety or stigma experienced from screening, except in those getting a diagnosis where the stigma (e.g., about
Very low

Patients considering screening (mainly females) may place more importance on the potential benefits than on the harms from screening, but the evidence is very uncertain with indication of variability. Transmission as the only benefit considered may still lead to the same assessment, as would consideration of both transmission and future reproductive health.
Very low Patients who have undergone screening, and are not diagnosed with $\mathrm{CT}$, may place more importance on the benefits than on the harms, but the evidence is very uncertain. 
Table 3 Summary of findings on patient preferences (key question 3) (Continued)

\begin{tabular}{|c|c|c|c|}
\hline Study designs & $\begin{array}{l}\text { Outcome } \\
\text { Studies; sample } \\
\text { size }\end{array}$ & Findings & $\begin{array}{l}\text { Certainty What does the evidence say? } \\
\text { of the } \\
\text { evidence }\end{array}$ \\
\hline & & $\begin{array}{l}\text { transmitting to others in social network) } \\
\text { and anxiety about infertility will likely } \\
\text { become relatively more important [91, } \\
102,103] \text {. It is unclear if the harms from a } \\
\text { diagnosis would deter people in these } \\
\text { studies from future screening. Because of } \\
\text { being told about the uncertain course of } \\
\text { CT infections and duration required to } \\
\text { cause infertility [91, 102], many women } \\
\text { who tested positive in two studies were } \\
\text { significantly concerned about the } \\
\text { possibility of being infertile and distressed } \\
\text { by their unanswered questions. One of } \\
\text { the studies found that the harm from } \\
\text { stigma after a diagnosis (or an anticipated } \\
\text { one) was the main driver for regular } \\
\text { repeat testing, to alleviate the feelings } \\
\text { [103]. }\end{array}$ & \\
\hline
\end{tabular}

Abbreviations: CT Chlamydia trachomatis, HSUV health-state utility value, IPNS in-patient nonsurgical, IPS in-patient surgical, NG Neisseria gonorrhoeae, OPAIP out-

patient after in-patient, PID pelvic inflammatory disease, QALY quality-adjusted life year, SDstandard deviation, TTO time trade off, VAS visual analog scale

${ }^{a}$ Reasons for ratings are explained in Additional file 6

qualitative methodologies. One study $(n=278)$ [85] used a questionnaire based on the Theory of Planned Behavior and quantitative analysis including the correlations of beliefs and attitudes with intentions to screen. Three other qualitative studies ( $n=15$ to 45 ) recruited participants, ages ranging from 16 to 39 years, of populationbased postal [102] or primary care (STI and family planning clinics) screening programs [91, 103], in one case only including those recently diagnosed with CT [91]. Most risk of bias domains were rated low risk of bias; main concerns were that several studies lacked descriptions of how much the perceived outcomes were thought to influence screening intentions or behaviors, and that most studies did not provide an accurate representation of the realistic risks for the outcomes-for example about the rare risk for infertility-to inform participant responses (Additional file 5).

Health-state utilities and rank order of benefits Values at the mid-range within values provided by the TTO methods were chosen as the best estimates of the utilities for each health state, with the exception of cervicitis where we only had the utility data from the indirect methods of the IOM study (Table 3). Variations between studies in the populations and methods did not help determine one best estimate within the range of TTO values (Additional file 6).

All of the health states probably have quite similar utility for females, without consideration of their duration. Based on estimates of QALY losses from using TTO utilities, infertility and chronic pelvic pain may be valued considerably more by females than ectopic pregnancy, PID, and cervicitis (Table 2 rank order outcome).
As described in Additional file 2, there are several assumptions that need to be made when using QALY losses, including that the utilities from TTO method do not already account for duration. The rank order was similar when sensitivity analysis was applied using QALY losses based on the utility values from the IOM study's indirect methods that estimate utility values without scenarios including a duration component.

Qualitative findings on relative importance of benefits versus harms Analysis of findings indicated that more comments and stronger concerns related to the potential benefits of reducing transmission "It benefits everybody...running around spreading it" [107] and reproductive complications "To stop long term effects so I can have babies" [87] than the potential harms, mainly from anxiety "The worry of having chlamydia" [84] and stigma "I would feel a bit ashamed...didn't pay attention...haven't been safe" [112] from screening or a diagnosis. This evidence is very uncertain due to serious risk of bias, inconsistency, and indirectness because most harms were anticipated rather than experienced, and studies did not consider specific benefit outcomes and imprecision in three small studies of those undergoing screening. Most studies did not present participants with any estimates of the risks for health consequences such that concern and anxiety over these may be based on misperceptions, of for example overestimated risks of infertility.

\section{Discussion}

We found that universal screening for CT, offered annually for 1 to 3 years in general populations 16 to 29 years 
of age using population-based (mailed invitation to screen) or opportunistic approaches in primary care, may make little-to-no difference in a females' risk of PID $(<2.5$ fewer or more cases per 1000) or ectopic pregnancy ( $<1$ fewer or more cases per 1000), although the evidence is very uncertain. These same approaches may make little-to-no difference for transmission $(<5$ fewer or more cases per 1000) when considering both sexes together (low certainty) or for females only (low to very low certainty); evidence for transmission in males is very uncertain. Findings from studies only enrolling females interested in or accepting screening suggest that important reductions in PID ( $>2.5$ fewer per 1000) may be attained in these scenarios. Intensive screening, at least biannually for 2-4 years, for CT and NG in highprevalence (e.g., $>11 \%$ CT and $>2.4 \%$ NG) female populations may reduce transmission of $\mathrm{CT}$ and $\mathrm{NG}$ to a moderate extent (>10 fewer per 1000) within these highrisk populations, but there was no evidence on whether a risk-based approach with screening only in high-risk individuals (e.g., based on some screen for risk factors) will impact transmission in the overall population eligible for screening. Across all KQs, our assessments and interpretations of effects in general and high-risk populations were based on the baseline prevalence of infection in the study populations or on estimates of the effects when assuming different prevalence rates, with the threshold for high-risk of 7\% for CT based on study, epidemiological data, and clinical input. The effects reflect a population perspective, and there was no evidence identified to directly inform one or more effective ways to choose specific individuals at increased risk to screen. Evidence was of very low certainty about the effects on transmission of CT and/or NG when considering both sexes or in males alone, or on infertility in females from offering a single CT screen. Evidence was not found for the outcomes of cervicitis, chronic pelvic pain (females), or infertility in males. No study reported on any of the clinical complications from screening for NG alone. The screening procedure, or receiving a diagnosis from screening, may cause a small proportion of the eligible population to experience harms of an uncertain duration and severity, mainly from feelings of stigmatization and anxiety especially about future risk for infertility. Offering patients screening conducted at home compared with at a clinic may make little-to-no difference in transmission, although the findings are very uncertain largely because of having to rely on treatment rates as a proxy for transmission. When using health-state utility data and accounting for the durations of each health state for the critical benefits of interest, we have low-to-moderate certainty that infertility and chronic pelvic pain are valued much more by female patients than are PID, ectopic pregnancy, and cervicitis. How patients weigh the potential benefits versus harms of screening is very uncertain, due to study limitations and inconsistency in findings, but there is some indication that risks to reproductive health and transmission are more important than the (often transient) harms of anxiety and stigmatization.

To some extent, the primary findings for PID from studies offering screening to the general population (whether accepted or not) may underestimate what could happen in practice care, mainly due to the studies' (i) usual care comparisons involving some screening, (ii) low screening rates, and (iii) assessment of PID in the entire source population, in which some people may not be sexually active. When considering the positive effects for this outcome from studies of those interested or accepting screening, it appears that benefits may be realized if higher rates of screening are achieved. The rates of CT testing for females in the Canadian province Ontario in 2011 were 21\% (15-19 years), 39\% (20-24 years), and 35\% (25-29 years) [120]. These numbers fell by about $5 \%$ in the year after changes to cervical cancer screening recommendations were released in 2012 by the cancer care agency in Ontario and Task Force, where the recommended starting age for screening increased to 21 and 25 years, respectively, and the frequency of screening was reduced to every 3 years [120]. The 2011 screening rates could likely be maintained or possibly surpassed if providers considered offering screening for CT during visits in addition to those involving a Papanicolaou (Pap) test $[120,121]$ and if they were aware of the higher than reported prevalence of CT, particularly in adolescents.

It is likely that the lower than expected screening rates in the Hocking trial were due to factors related to both providers and patients. Rates of screening completion if requested by a provider were $80 \%$; less likely to follow through and be tested for CT were males, people aged 16-19 years, those living in areas of greater socioeconomic disadvantage, and those attending clinics without on-site pathology collection [122]. Whether a provider requested a test was likely influenced by numerous factors, including but not limited to whether a Pap smear was also provided, whether they felt comfortable or thought the context was suitable for questioning patients about sexual activity, or whether nurses as well as physicians were included in the process $[123,124]$. The test positivity rates (about $10 \% \mathrm{CT}$ ) during screening in the trial were twice as high as the general prevalence rate at baseline measured through surveys; this suggests an informal selection process by health care providers for screening rather than the universal approach of the protocol, although this method did not appear to find enough cases to impact PID or prevalence [7].

The findings for effectiveness of screening are largely applicable to a broad age range from 15 to 29 years. 
Only one trial [8] performed subgroup analysis for differing effects on prevalence by age and found no differences. More evidence on whether the effects vary by age would be useful to help determine the best ages to start and stop universal screening.

The thresholds for an important effect, used for interpreting the magnitude and certainty of the evidence for the benefit outcomes in KQ1, were created by working group clinicians and topic experts and may not accurately reflect the patient perspective. Had different thresholds been used, the conclusions for some outcomes would be different. For example, a higher threshold for PID (e.g., $\geq 6$ or 7 fewer cases per 1000 for a minimally important difference) would lead to findings of little-to-no difference (still having low certainty) for acceptors of screening at general-risk, and to a higher certainty of little-to-no difference for universal offering of screening to the general-risk populations. The thresholds were developed using estimates of CT prevalence in the general Canadian population and data on the natural course of the infections, recognizing there are limitations particularly from difficulties and challenges in obtaining long-term data on women with untreated infections [27].

We found very few studies comparing the effectiveness of different screening approaches (KQ2) and none that compared strategies differing by intensity. The body of evidence in KQ1 (screening versus no screening) suggests that a reduction in PID may be attainable for females interested and/or accepting one screening test with 1-year follow-up, indicates that annual testing may be sufficient. Some data suggest that more frequent testing may be more beneficial. The one trial in KQ1 that tested for CT at baseline in both study arms (freezing the samples in the control arm until study completion) found that while fewer females had PID in the screening versus control arm at 1-year follow-up, most episodes of PID (79\%) in the study population occurred in females who tested negative for CT at baseline [28]. Some cases of PID likely arose in the women acquiring a CT infection over the year after screening; others were likely caused by other organisms (e.g., Mycoplasma genitalium, microorganisms associated with bacterial vaginosis, and respiratory and enteric pathogens) [26, 31]. Likewise, the two trials $[60,89]$ showing benefit for transmission also suggest that more than annual screening may be necessary. Because the study populations in these trials were at high risk for CT and NG infections (e.g., multiple sexual partners) and screening was in outreach populations, it is difficult to determine whether the effects may be attributed more to the intensity of screening or to the target population and/or setting. Duration of screening may be a key determinant that was not directly addressed in the trials. For screening programs in general, and especially when considering transmission effects, there is a lag time expected before seeing the full effect of the major outcomes averted as a result of screening [125]. After harmonization of disease-specific parameters across three modeling studies [125-127], substantial reductions in CT prevalence may require sustaining screening at low-to-moderate rates $(20 \%)$ in the general population for at least 5 to 10 years [50]. Lastly, because of the transmission dynamics and sexual transmissibility of this infection, screening males may be critical to prevent CT (and its complications) in females. The screening rates for males were approximately half of those for females in the trials reporting no reduction in PID or transmission of CT $[8,9,12,59]$.

Our results about CT screening effectiveness differ somewhat from other recent systematic reviews, and much of this may have resulted from differences in inclusion criteria and analytic approach. A 2016 Cochrane review by Low et al. [65] and another review commissioned by the European Centre for Disease Prevention and Control led by the same author [27] found 32\% and $34 \%$ relative reductions in PID (95\% CIs 6 to 51\% and 10 to $55 \%$ ), respectively, from pooling four RCTs [28, 59 , $105,108]$ that we chose not to pool because of methodological differences (i.e., offer-to-screen versus acceptors of screening). We also included the more recent results from the Hocking RCT, which were considered the most direct of the evidence to inform the Task Force that prioritized an offer-to-screen approach. Further, although the statistical heterogeneity ( $I^{2}$ value $\left.11 \%\right)$ was found to be low (in support of pooling the four RCTs), the differences between the magnitudes in effect when using absolute effects and when compared with a threshold (as we relied upon for assessing inconsistency) would be substantial. These authors' findings for transmission in general populations (low certainty for little-to-no difference) were similar to ours, despite that we included the Hocking RCT results and an additional RCT [12], which did not meet their inclusion criteria. We have slightly more certainty (low-to-moderate versus their low certainty) about the findings for CT prevalence in high prevalence female populations because of the consistency found between the two studies we included [60,89] versus their inclusion of a single study [60]. Only including RCTs, the Low et al. review did not find evidence on harms of CT screening. Neither of these reviews considered the effectiveness of screening for NG. The most recent published systematic review on this topic (2014) conducted for the United States Preventive Services Task Force focused on screening for both CT and NG in asymptomatic people [19]. This population differed from ours in that we considered eligible people not seeking testing for symptoms, and we did not require confirmation of their asymptomatic status, which can be considered a screening test in itself. Although the USPSTF review 
authors mention the results from two RCTs included in the previous USPSTF review (Scholes and Ostergaard, neither excluding females with symptoms), their conclusions that screening may reduce PID focused on results in a subset of the participants without symptoms at baseline in the Oakeshott RCT (relative risk, 0.39 [95\% CI, 0.14 to 1.08]; received from author contact). Further, although uncontrolled studies were newly eligible for harms from screening in this update, several were excluded $(n=4)$ based on the population not being asymptomatic. Many other reviews have been published, although typically focus on particular settings and/or comparisons [56, 128, 129]. The 2015 Cochrane review [128] on home versus clinic specimen collection for $\mathrm{CT}$ screening came to similar conclusions as ours for KQ2, when looking at case management (i.e., identification and treatment of cases) for which there may be little-to-no difference. These authors also looked at the number of persons tested using each approach, with findings varying widely across the studies, ranging from 30 to $96 \%$ in the home group and 6 to $97 \%$ in the clinic group (low-quality evidence).

Systematic reviews are threatened by risks of selective reporting bias (e.g., studies only reporting positive outcomes), publication bias-whereby unexpectedly strong results from large trials are selectively published, and selection bias. Our comprehensive search, independent review for study selection, and negative findings from several studies suggest that these factors were likely not relevant $[130,131]$. Several studies had either trial registration or published protocols to help assess selective reporting and/or missing outcomes. Effect sizes in language-restricted reviews have shown to not differ significantly from those without restrictions [130, 131]. Many trials had methodological limitations introducing some risk of bias, and several aspects of the study populations, setting, interventions, and control groups introduced indirectness. Our findings for the absolute effects on PID in high-risk populations should be interpreted with caution; we are uncertain whether the RR from studies in a general-risk population, used in calculations for the absolute effects, applies to the high-risk population. Our main conclusion of very low certainty from the data on PID in trials offering screening to general-risk populations is based on absolute effects calculated using estimated control PID event rates, based on evidence on the natural history of PID and assumed CT prevalence rates, rather than the study data. Those preferring to use study data for these conclusions should note our low-to-moderate certainty of little to no difference in this situation.

Apart from the limitations of having very low to low certainty evidence across most outcomes and comparisons, the studies included in this review do not provide much if any insight on whether or how to target screening to individuals at higher risk (e.g., based on behavioral risk factors or identification with groups at disproportionate risk such as MSM or transgender people) where the benefits may be realized at an individual and population level. Studies on the benefits and harms of screening specific to these populations in primary care settings would be particularly informative, as would studies directly comparing different screening intervals and target ages, and comparing screening in both sexes versus only females.

\section{Conclusions}

For screening benefits, most of the evidence examined about screening for CT and/or NG offers low or very low certainty about the effects on outcomes and comparisons critical for decision making about offering screening in primary care. Indirectness from use of comparison groups receiving some screening, from lack of complete outcome ascertainment, and from use of outreach settings is a major contributor to uncertainty. Prevalence of the infections and screening rates appear to be important moderators of effect on the benefits, but direct evidence on the impact on the general population from targeting screening to high-risk individuals was not found. For screening harms, although the evidence suggested screening may cause a small-to-moderate number of people to experience some degree of harm, mainly due to feelings of stigmatization and anxiety about future infertility risk, there is uncertainty about the extent, severity, and duration of harms from screening when considering the overall population eligible for screening. If preventing clinical consequences from CT infection is a priority, it appears that screening in primary care may have benefits for reducing PID and, through its natural course, long-term sequelae. The magnitude of the effects expected from screening in primary care in Canada, though, is uncertain and may require some speculation as may the degree to which the benefits outweigh the harms. Direct evidence about which screening strategies and intervals to use, which age to start and stop screening, and whether screening males in addition to females is necessary to prevent clinical outcomes is scarce, and further research in these areas would be informative. For patient preferences, the evidence indicates that the potential benefits from screening appear to outweigh the possible harms, although there may be some variability between patients. Apart from the evidence in this review, information on factors related to equity, acceptability, implementation, cost/resources, and feasibility in the Canadian context will support recommendations made by the Task Force.

\section{Abbreviations}

CCT: Controlled clinical trial; Cl: Confidence interval; CT: Chlamydia trachomatis; FSWs: Female sex workers; GRADE: Grading of 
Recommendations Assessment, Development and Evaluation; HIV: Human immunodeficiency virus; ICC: Intraclass correlation coefficient; KQ: Key question; MSM: Men who have sex with men; NG: Neisseria gonorrhoeae; OR: Odds ratio; PID: Pelvic inflammatory disease; PHAC: Public Health Agency of Canada; RCT: Randomized controlled trial; RR: Relative risk; STI: Sexually transmitted infection

\section{Supplementary Information}

The online version contains supplementary material available at https://doi. org/10.1186/s13643-021-01658-w.

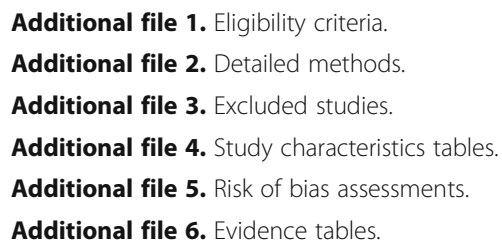

\section{Acknowledgements}

We thank the Task Force members serving on this topic's Working Group (Ainsley Moore [Chair], Donna Reynolds, John Riva, Guylene Thériault, Brett Thombs, Brenda Wilson) and the topic experts (Ameeta Singh, Tom Wong, Ann N. Burchell, Jo-Anne Dillon) for providing clinical input, assistance with interpreting the findings including developing thresholds for clinical importance, and providing input on the manuscript. We would like to acknowledge the Task Force members who are not in the Working Group: Heather Colquhoun, Roland Grad, Stéphane Groulx, Michael Kidd, Scott Klarenbach, Eddy Lang, John Leblanc, Nav Persaud. We thank librarians Ms Robin Featherstone for developing and running the original search, Tara Landry for peer-reviewing the search, and Diana Keto-Lambert for updating the search. We also thank Cydney Johnson for screening.

\section{Authors' contributions}

JP participated in all activities of the review, drafted all sections of this manuscript, and is the guarantor of the review. LH contributed to the design of the review and provided methodological input across all sections. AW performed risk of bias assessments, extracted and analyzed data, and performed GRADE assessments. TM screened studies and assisted with data extraction. MG screened studies and assisted with data extraction and analysis for KQ1 on harms. BV helped analyze the data for KQs 1 and 2. All authors have reviewed the manuscript and approve the submission of this version of the protocol.

\section{Funding}

This review was conducted for the Public Health Agency of Canada (PHAC); however, it does not necessarily represent the views of the Government of Canada. Staff of the Global Health and Guidelines Division at the Public Health Agency of Canada (Gregory Traversy, Prinon Rahman, Susan Courage, Rachel Rodin, Melissa Subnath, Elizabeth Rolland-Harris) assisted with developing the scope of the review and/or have reviewed the manuscript, but did not take part in the selection of studies, data extraction, analysis, or interpretation of the findings.

\section{Availability of data and materials}

All data generated or analyzed during this study are included in this published article and its additional files.

\section{Declarations}

Ethics approval and consent to participate

Not applicable.

\section{Consent for publication}

Not applicable.

\section{Competing interests}

The authors declare that they have no competing interests.
Received: 23 December 2019 Accepted: 31 March 2021 Published online: 19 April 2021

\section{References}

1. Choudhri Y, Miller J, Sandhu J, Leon A, Aho J. Chlamydia in Canada, 20102015. Can Commun Dis Rep. 2018;44(2):49-54. https://doi.org/10.14745/ccdr. v44i02a03.

2. Choudhri Y, Miller J, Sandhu J, Leon A, Aho J. Gonorrhea in Canada, 20102015. Can Commun Dis Rep. 2018;44(2):37-42. https://doi.org/10.14745/ccdr. v44i02a01.

3. Public Health Agency of Canada. Notifiable disease chart. Rate per 100,000 of reported cases by age group in Canada, grouped by sex. Chlamydia, 2017. https://diseases.canada.ca/notifiable/. Accessed 11 Sept 2020.

4. Public Health Agency of Canada. Report on sexually transmitted infections in Canada: 2013-2014. Ottawa: Centre for Communicable Diseases and Infection Control, Infectious Disease Prevention and Control Branch, PHAC 2017. https://www.canada.ca/en/public-health/services/publications/disea ses-conditions/report-sexually-transmitted-infections-canada-2013-14.html. Accessed 14 Sept 2020

5. Dukers-Muijrers NH, Schachter J, van Liere GA, Wolffs PF, Hoebe CJ. What is needed to guide testing for anorectal and pharyngeal Chlamydia trachomatis and Neisseria gonorrhoeae in women and men? Evidence and opinion. BMC Infect Dis. 2015;15(1):533. https://doi.org/10.1186/s12879-01 5-1280-6.

6. Lutz AR. Screening for asymptomatic extragenital gonorrhea and chlamydia in men who have sex with men: significance, recommendations, and options for overcoming barriers to testing. LGBT Health. 2015;2(1):27-34. https://doi.org/10.1089/lgbt.2014.0056.

7. Lewis D, Newton DC, Guy RJ, Ali H, Chen MY, Fairley CK, et al. The prevalence of Chlamydia trachomatis infection in Australia: a systematic review and meta-analysis. BMC Infect Dis. 2012;12(1):113. https://doi.org/1 0.1186/1471-2334-12-113.

8. Hocking JS, Temple-Smith M, Guy R, Donovan B, Braat S, Law M, et al. Population effectiveness of opportunistic chlamydia testing in primary care in Australia: a cluster-randomised controlled trial. Lancet. 2018;392(10156): 1413-22. https://doi.org/10.1016/S0140-6736(18)31816-6.

9. van den Broek IV, van Bergen JE, Brouwers EE, Fennema JS, Gotz HM, Hoebe $\mathrm{CJ}$, et al. Effectiveness of yearly, register based screening for chlamydia in the Netherlands: controlled trial with randomised stepped wedge implementation. BMJ. 2012;345:e4316. https://doi.org/10.1136/bmj.e4316.

10. Statistics Canada. 2013/14 Canadian Community Health Survey. Table 7. Canadians who used a condom during last sexual intercourse, by age group and sex, household population aged 15 to 49, 2013/2014. http:// www.statcan.gc.ca/daily-quotidien/150624/t007b-eng.htm. Accessed 11 Sept 2020.

11. Lee $\mathrm{V}$, Tobin JM, Foley E. Relationship of cervical ectopy to chlamydia infection in young women. J Fam Plann Reprod Health Care. 2006;32(2): 104-6. https://doi.org/10.1783/147118906776276440.

12. Hodgins S, Peeling RW, Dery S, Bernier F, LaBrecque A, Proulx JF, et al. The value of mass screening for chlamydia control in high prevalence communities. Sex Transm Infect. 2002;78(Suppl 1):i64-8. https://doi.org/1 0.1136/sti.78.suppl_1.i64.

13. World Health Organization. Prevention and treatment of HIV and other sexually transmitted infections among men who have sex with men and transgender people. Recommendations for a public health approach 2011. Geneva; 2011. http://www.who.int/hiv/pub/guidelines/msm_guidelines2 011/en/. Accessed 11 Sept 2020

14. Creighton S, Tenant-Flowers M, Taylor CB, Miller R, Low N. Co-infection with gonorrhoea and chlamydia: how much is there and what does it mean? Int J STD AIDS. 2003;14(2):109-13. https://doi.org/10.1258/095646203321156872.

15. Forward KR. Risk of coinfection with Chlamydia trachomatis and Neisseria gonorrhoeae in Nova Scotia. Can J Infect Dis Med Microbiol. 2010;21(2):e846. https://doi.org/10.1155/2010/760218.

16. Lyss SB, Kamb ML, Peterman TA, Moran JS, Newman DR, Bolan G, et al. Chlamydia trachomatis among patients infected with and treated for Neisseria gonorrhoeae in sexually transmitted disease clinics in the United States. Ann Intern Med. 2003;139(3):178-85. https://doi.org/10.7326/0003-4 819-139-3-200308050-00007.

17. McMillan A, Manavi K, Young H. Concurrent gonococcal and chlamydial infections among men attending a sexually transmitted diseases clinic. Int J STD AIDS. 2005;16(5):357-61. https://doi.org/10.1258/0956462053888925. 
18. Ginocchio CC, Chapin K, Smith JS, Aslanzadeh J, Snook J, Hill CS, et al. Prevalence of Trichomonas vaginalis and coinfection with Chlamydia trachomatis and Neisseria gonorrhoeae in the United States as determined by the Aptima Trichomonas vaginalis nucleic acid amplification assay. J Clin Microbiol. 2012;50(8):2601-8. https://doi.org/10.1128/JCM.00748-12.

19. Zakher B, Cantor AG, Pappas M, Daeges M, Nelson HD. Screening for gonorrhea and chlamydia: a systematic review for the U.S. Preventive Services Task Force. Ann Intern Med. 2014;161(12):884-93. https://doi.org/10. 7326/M14-1022.

20. Rekart ML, Gilbert M, Meza R, Kim PH, Chang M, Money DM, et al. Chlamydia public health programs and the epidemiology of pelvic inflammatory disease and ectopic pregnancy. J Infect Dis. 2013;207(1):30-8. https://doi.org/10.1093/infdis/jis644.

21. Price MJ, Ades AE, Angelis DD, Welton NJ, Macleod J, Soldan K, et al. Mixture-of-exponentials models to explain heterogeneity in studies of the duration of Chlamydia trachomatis infection. Stat Med. 2013;32(9):1547-60. https://doi.org/10.1002/sim.5603.

22. Grad YH, Goldstein E, Lipsitch M, White PJ. Improving control of antibioticresistant gonorrhea by integrating research agendas across disciplines: key questions arising from mathematical modeling. J Infect Dis. 2016;213(6): 883-90. https://doi.org/10.1093/infdis/jiv517.

23. Darville T, Hiltke TJ. Pathogenesis of genital tract disease due to Chlamydia trachomatis. J Infect Dis. 2010:201(S2):S114-25.

24. McElligott KA. Mortality from sexually transmitted diseases in reproductiveaged women: United States, 1999-2010. Am J Public Health. 2014;104(8): e101-5. https://doi.org/10.2105/AJPH.2014.302044.

25. Pelvic Inflammatory Disease (PID) - CDC Fact Sheet. https://www.cdc.gov/ std/pid/stdfact-pid-detailed.htm. Accessed 11 Sept 2020.

26. Price MJ, Ades AE, Welton NJ, Simms I, Macleod J, Horner PJ. Proportion of pelvic inflammatory disease cases caused by Chlamydia trachomatis: consistent picture from different methods. J Infect Dis. 2016;214(4):617-24. https://doi.org/10.1093/infdis/jiw178.

27. European Centre for Disease Prevention and Control. Chlamydia control in Europe: literature review. Stockholm: ECDC; 2014. https://www.ecdc.europa. eu/en/publications-data/chlamydia-control-europe-literature-review. Accessed 11 Sept 2020

28. Oakeshott P, Kerry S, Aghaizu A, Atherton H, Hay S, Taylor-Robinson D, et al. Randomised controlled trial of screening for Chlamydia trachomatis to prevent pelvic inflammatory disease: the POPI (prevention of pelvic infection) trial. BMJ. 2010;340(apr08 1):c1642. https://doi.org/10.1136/bmj.c1642.

29. Price MJ, Ades AE, De Angelis D, Welton NJ, Macleod J, Soldan K, et al. Risk of pelvic inflammatory disease following Chlamydia trachomatis infection: analysis of prospective studies with a multistate model. Am J Epidemiol. 2013;178(3):484-92. https://doi.org/10.1093/aje/kws583.

30. Trent M, Bass D, Ness RB, Haggerty C. Recurrent PID, subsequent STI, and reproductive health outcomes: findings from the PID evaluation and clinical health (PEACH) study. Sex Transm Dis. 2011;38(9):879-81. https://doi.org/1 0.1097/OLQ.0b013e31821f918c.

31. Brunham RC, Gottlieb SL, Paavonen J. Pelvic inflammatory disease. N Engl J Med. 2015;372(21):2039-48. https://doi.org/10.1056/NEJMra1411426.

32. Jackson LJ, Auguste P, Low N, Roberts TE. Valuing the health states associated with Chlamydia trachomatis infections and their sequelae: a systematic review of economic evaluations and primary studies. Value Health. 2014;17(1):116-30. https://doi.org/10.1016/j.jval.2013.10.005.

33. Fode M, Fusco F, Lipshultz L, Weidner W. Sexually transmitted disease and male infertility: a systematic review. Eur Urol Focus. 2016;2(4):383-93. https://doi.org/10.1016/j.euf.2016.08.002.

34. Bignell C, Unemo M. 2012 European guideline on the diagnosis and treatment of gonorrhoea in adults. Int J STD AIDS. 2013;24(2):85-92. https:// doi.org/10.1177/0956462412472837.

35. Fleming DT, Wasserheit JN. From epidemiological synergy to public health policy and practice: the contribution of other sexually transmitted diseases to sexual transmission of HIV infection. Sex Transm Infect. 1999;75(1):3-17. https://doi.org/10.1136/sti.75.1.3.

36. Chun HM, Carpenter RJ, Macalino GE, Crum-Cianflone NF. The role of sexually transmitted infections in HIV-1 progression: a comprehensive review of the literature. J Sex Transm Dis. 2013:176459.

37. Sexton J, Garnett G, Rottingen JA. Metaanalysis and metaregression in interpreting study variability in the impact of sexually transmitted diseases on susceptibility to HIV infection. Sex Transm Dis. 2005;32(6):351-7. https:// doi.org/10.1097/01.olq.0000154504.54686.d1.
38. Ng BE, Butler LM, Horvath T, Rutherford GW. Population-based biomedical sexually transmitted infection control interventions for reducing HIV infection. Cochrane Database Syst Rev. 2011;(3):CD001220.

39. Hosenfeld CB, Workowski KA, Berman S, Zaidi A, Dyson J, Mosure D, et al. Repeat infection with chlamydia and gonorrhea among females: a systematic review of the literature. Sex Transm Dis. 2009;36(8):478-89. https://doi.org/10.1097/OLQ.0b013e3181a2a933.

40. Hillis SD, Owens LM, Marchbanks PA, Amsterdam LF, Mac Kenzie WR. Recurrent chlamydial infections increase the risks of hospitalization fo ectopic pregnancy and pelvic inflammatory disease. Am J Obstet Gynecol. 1997;176(1):103-7. https://doi.org/10.1016/S0002-9378(97)80020-8.

41. Westrom L, Joesoef R, Reynolds G, Hagdu A, Thompson SE. Pelvic inflammatory disease and fertility. A cohort study of 1,844 women with laparoscopically verified disease and 657 control women with normal laparoscopic results. Sex Transm Dis. 1992;19(4):185-92. https://doi.org/10.1 097/00007435-199207000-00001.

42. Geisler WM. Diagnosis and management of uncomplicated Chlamydia trachomatis infections in adolescents and adults: summary of evidence reviewed for the 2015 Centers for Disease Control and Prevention Sexually Transmitted Diseases Treatment Guidelines. Clin Infect Dis. 2015;61(Suppl 8): S774-84. https://doi.org/10.1093/cid/civ694.

43. Chan PA, Robinette A, Montgomery M, Almonte A, Cu-Uvin S, Lonks JR, et al. Extragenital infections caused by Chlamydia trachomatis and Neisseria gonorrhoeae: a review of the literature. Infect Dis Obstet Gynecol. 2016; 2016:5758387.

44. Lau CY, Qureshi AK. Azithromycin versus doxycycline for genital chlamydial infections: a meta-analysis of randomized clinical trials. Sex Transm Dis. 2002;29(9):497-502. https://doi.org/10.1097/00007435-200209000-00001.

45. Paez-Canro C, Alzate JP, Gonzalez LM, Rubio-Romero JA, Lethaby A, Gaitan HG. Antibiotics for treating urogenital Chlamydia trachomatis infection in men and non-pregnant women. Cochrane Database Syst Rev. 2019;1(1); CD010871.

46. Newman LM, Moran JS, Workowski KA. Update on the management of gonorrhea in adults in the United States. Clin Infect Dis. 2007;44(Suppl 3): S84-101. https://doi.org/10.1086/511422.

47. Barbee LA, Kerani RP, Dombrowski JC, Soge OO, Golden MR. A retrospective comparative study of 2-drug oral and intramuscular cephalosporin treatment regimens for pharyngeal gonorrhea. Clin Infect Dis. 2013;56(11): 1539-45. https://doi.org/10.1093/cid/cit084.

48. Singh AE, Gratrix J, Martin I, Friedman DS, Hoang L, Lester R, et al. Gonorrhea treatment failures with oral and injectable expanded spectrum cephalosporin monotherapy vs dual therapy at 4 Canadian sexually transmitted infection clinics, 2010-2013. Sex Transm Dis. 2015;42(6):331-6. https://doi.org/10.1097/OLQ.0000000000000280.

49. Unemo M, Jensen JS. Antimicrobial-resistant sexually transmitted infections: gonorrhoea and Mycoplasma genitalium. Nat Rev Urol. 2017;14(3):139-52. https://doi.org/10.1038/nrurol.2016.268.

50. Althaus CL, Turner KM, Schmid BV, Heijne JC, Kretzschmar M, Low N. Transmission of Chlamydia trachomatis through sexual partnerships: a comparison between three individual-based models and empirical data. J R Soc Interface. 2012;9(66):136-46. https://doi.org/10.1098/rsif.2011.0131.

51. Gudka S, Afuwape FE, Wong B, Yow XL, Anderson C, Clifford RM. Chlamydia screening interventions from community pharmacies: a systematic review. Sex Health. 2013;10(3):229-39. https://doi.org/10.1071/SH12069.

52. Jenkins WD, Zahnd W, Kovach R, Kissinger P. Chlamydia and gonorrhea screening in United States emergency departments. J Emerg Med. 2013; 44(2):558-67. https://doi.org/10.1016/j.jemermed.2012.08.022.

53. Hengel B, Jamil MS, Mein JK, Maher L, Kaldor JM, Guy RJ. Outreach for chlamydia and gonorrhoea screening: a systematic review of strategies and outcomes. BMC Public Health. 2013;13(1):1040. https://doi.org/10.1186/14 71-2458-13-1040.

54. Jamil MS, Bauer HM, Hocking JS, Ali H, Wand H, Walker J, et al. Chlamydia screening strategies and outcomes in educational settings: a systematic review. Sex Transm Dis. 2014;41(3):180-7. https://doi.org/10.1097/OLQ. 0000000000000095 .

55. Jamil MS, Hocking JS, Bauer HM, Ali H, Wand H, Smith K, et al. Home-based chlamydia and gonorrhoea screening: a systematic review of strategies and outcomes. BMC Public Health. 2013;13(1):189. https://doi.org/10.1186/14 71-2458-13-189.

56. Lunny C, Taylor D, Hoang L, Wong T, Gilbert M, Lester R, et al. Self-collected versus clinician-collected sampling for chlamydia and gonorrhea screening: 
a systemic review and meta-analysis. PLoS ONE. 2015;10(7):e0132776. https://doi.org/10.1371/journal.pone.0132776.

57. Pogany L, Romanowski B, Robinson J, Gale-Rowe M, Latham-Carmanico C, Weir C, et al. Management of gonococcal infection among adults and youth: new key recommendations. Can Fam Physician. 2015;61:86973, e451-6.

58. Public Health Agency of Canada. Canadian Guidelines on Sexually Transmitted Infections. https://www.canada.ca/en/public-health/services/ infectious-diseases/sexual-health-sexually-transmitted-infections/canadianguidelines/sexually-transmitted-infections.html. Accessed 11 Sept 2020

59. Andersen B, van Valkengoed I, Sokolowski I, Moller JK, Ostergaard L, Olesen F. Impact of intensified testing for urogenital Chlamydia trachomatis infections: a randomised study with 9-year follow-up. Sex Transm Infect. 2011;87(2):156-61. https://doi.org/10.1136/sti.2010.042192.

60. Garcia PJ, Holmes KK, Carcamo CP, Garnett GP, Hughes JP, Campos PE, et al. Prevention of sexually transmitted infections in urban communities (Peru PREVEN): a multicomponent community-randomised controlled trial. Lancet. 2012;379(9821):1120-8. https://doi.org/10.1016/S0140-6736(11)61846-1.

61. Zhang Y, Alonso-Coello P, Guyatt GH, Yepes-Nunez JJ, Akl EA, Hazlewood G, et al. GRADE Guidelines: 19. Assessing the certainty of evidence in the importance of outcomes or values and preferences-risk of bias and indirectness. J Clin Epidemiol. 2019;111:94-104. https://doi.org/10.1016/j. jclinepi.2018.01.013.

62. Zhang Y, Coello PA, Brozek J, Wiercioch W, Etxeandia-lkobaltzeta I, Akl EA, et al. Using patient values and preferences to inform the importance of health outcomes in practice guideline development following the GRADE approach. Health Qual Life Outcomes. 2017;15(1):52. https://doi.org/10.1186/ s12955-017-0621-0.

63. Zhang Y, Coello PA, Guyatt GH, Yepes-Nunez JJ, Akl EA, Hazlewood G, et al. GRADE guidelines: 20. Assessing the certainty of evidence in the importance of outcomes or values and preferences-inconsistency, imprecision, and other domains. J Clin Epidemiol. 2019;111:83-93. https:// doi.org/10.1016/j.jclinepi.2018.05.011.

64. Schunemann H, Brozek J, Guyatt G, Oxman A: GRADE handbook. 2013. https:// gdt.gradepro.org/app/handbook/handbook.html. Accessed 14 Sept 2020.

65. Low N, Redmond S, Uuskula A, van Bergen J, Ward H, Andersen B, et al. Screening for genital chlamydia infection. Cochrane Database Syst Rev. 2016;9:CD010866.

66. Pillay J, Moore A, Rahman P, Lewin G, Reynolds D, Riva J, et al. Screening for chlamydia and/or gonorrhea in primary health care: protocol for systematic review. Syst Rev. 2018;7(1):248. https://doi.org/10.1186/s13643-018-0904-5.

67. Moher D, Liberati A, Tetzlaff J, Altman DG. Preferred reporting items for systematic reviews and meta-analyses: the PRISMA statement. PLoS Med. 2009;6(7):e1000097. https://doi.org/10.1371/journal.pmed.1000097.

68. United Nations Development Programme. Human Development Reports: Human Development Index (HDI) Ranking 2018. New York: United Nations Development Programme; 2018. http://hdr.undp.org/en/2018-update Accessed 11 Sept 2020

69. Glassman JR, Potter SC, Baumler ER, Coyle KK. Estimates of intraclass correlation coefficients from longitudinal group-randomized trials of adolescent HIV/STI/pregnancy prevention programs. Health Educ Behav. 2015;42(4):545-53. https://doi.org/10.1177/1090198114568308.

70. Schunemann H, Brozek J, Guyatt G, Oxman A: GRADE handbook: 4.3 summary of findings table. 2013. http://gdt.guidelinedevelopment.org/app/ handbook/handbook.html. Accessed 14 Sept 2020

71. Egger M, Davey Smith G, Schneider M, Minder C. Bias in meta-analysis detected by a simple, graphical test. Bmj. 1997;315(7109):629-34. Egger M, Davey Smith G, Schneider M, Minder C. Bias in meta-analysis detected by a simple, graphical test. BMJ. 1997;315:629-34.

72. Higgins J, Green S. Cochrane handbook for systematic reviews of interventions. Version 5.1.0. 2011. http://training.cochrane.org/handbook. Accessed 11 Sept 2020.

73. National Institute for Health and Care Excellence: Appendix D methodology checklist: cohort studies. The social care guidance manual. PMG10. 2016 https://www.nice.org.uk/process/pmg10/chapter/appendix-d-methodologychecklist-cohort-studies\#checklist-3. Accessed 11 Sept 2020.

74. Wells GA, Shea B, O'Connell D, Petersen J, Welch V, Losos M, et al. The Newcastle-Ottawa Scale (NOS) for assessing the quality of nonrandomized studies in meta-analyses. Canada: Department of Epidemiology and Community Medicine, University of Ottawa. http://www.ohri.ca/programs/ clinical_epidemiology/oxford.asp. Accessed 11 Sept 2020
75. Centre for Evidence-Based Management (CEBMa). Appraisal of a crosssectional study (survey). Leiden: The Netherlands; 2018. https://www.cebma. org/resources-and-tools/what-is-critical-appraisal/. Accessed 11 Sept 2020

76. Critical Appraisal Skills Programme. CASP qualitative checklist. Oxford: Middleway; 2018. https://casp-uk.net/casp-tools-checklists/. Accessed 11 Sept 2020

77. Guyatt GH, Oxman AD, Schunemann HJ, Tugwell P, Knottnerus A. GRADE guidelines: a new series of articles in the Journal of Clinical Epidemiology. J Clin Epidemiol. 2011;64(4):380-2. https://doi.org/10.101 6/j.jclinepi.2010.09.011.

78. Hultcrantz M, Rind D, Akl EA, Treweek S, Mustafa RA, lorio A, et al. The GRADE Working Group clarifies the construct of certainty of evidence. J Clin Epidemiol. 2017;87:4-13. https://doi.org/10.1016/j.jclinepi.2017.05.006.

79. Murad MH, Mustafa RA, Schunemann HJ, Sultan S, Santesso N. Rating the certainty in evidence in the absence of a single estimate of effect. Evid Based Med. 2017;22(3):85-7. https://doi.org/10.1136/ebmed-2017-110668.

80. Santesso N, Glenton C, Dahm P, Garner P, Akl E, Alper B, et al. GRADE guidelines 26: informative statements to communicate the findings of systematic reviews of interventions. J Clin Epidemiol. 2020;119:126-35.

81. Andersson N, Carre H, Janlert U, Boman J, Nylander E. Gender differences in the well-being of patients diagnosed with Chlamydia trachomatis: a crosssectional study. Sex Transm Infect. 2018;94(6):401-5. https://doi.org/10.1136/ sextrans-2017-053229.

82. Balfe M, Brugha R, O'Donovan D, O'Connell E, Vaughan D. Young women's decisions to accept chlamydia screening: influences of stigma and doctorpatient interactions. BMC Public Health. 2010;10(1):425. https://doi.org/10.11 86/1471-2458-10-425.

83. Barth KR, Cook RL, Downs JS, Switzer GE, Fischhoff B. Social stigma and negative consequences: factors that influence college students' decisions to seek testing for sexually transmitted infections. J Am Coll Health. 2002;50(4): 153-9. https://doi.org/10.1080/07448480209596021.

84. Booth AR, Harris PR, Goyder E, Norman P. Beliefs about chlamydia testing amongst young people living in relatively deprived areas. J Public Health (Oxf). 2013;35:213-22.

85. Booth AR, Norman P, Harris PR, Goyder E. Using the Theory of Planned Behavior to identify key beliefs underlying chlamydia testing intentions in a sample of young people living in deprived areas. J Health Psychol. 2015; 20(9):1229-39. https://doi.org/10.1177/1359105313510335.

86. Campbell R, Mills N, Sanford E, Graham A, Low N, Peters TJ, et al. Does population screening for Chlamydia trachomatis raise anxiety among those tested? Findings from a population based chlamydia screening study. BMC Public Health. 2006;6:106.

87. Chacko MR, von Sternberg K, Velasquez MM, Wiemann CM, Smith PB, DiClemente R. Young women's perspective of the pros and cons to seeking screening for chlamydia and gonorrhea: an exploratory study. J Pediatr Adolesc Gynecol. 2008;21 (4):187-93. https://doi.org/10.1016/j.jpag.2007.08.009.

88. Clark KL, Howell MR, Li Y, Powers T, McKee KT Jr, Quinn TC, et al. Hospitalization rates in female US Army recruits associated with a screening program for Chlamydia trachomatis. Sex Transm Dis. 2002;29(1):1-5. https:// doi.org/10.1097/00007435-200201000-00001.

89. Cohen DA, Nsuami M, Martin DH, Farley TA. Repeated school-based screening for sexually transmitted diseases: a feasible strategy for reaching adolescents. Pediatrics. 1999;104(6):1281-5. https://doi.org/10.1542/peds.104. 6.1281 .

90. Cook RL, Ostergaard L, Hillier SL, Murray PJ, Chang CC, Comer DM, et al. Home screening for sexually transmitted diseases in high-risk young women: randomised controlled trial. Sex Transm Infect. 2007;83(4):286-91. https://doi.org/10.1136/sti.2006.023762.

91. Duncan B, Hart G, Scoular A, Bigrigg A. Qualitative analysis of psychosocial impact of diagnosis of Chlamydia trachomatis: implications for screening. BMJ. 2001;322(7280):195-9. https://doi.org/10.1136/bmj.322.7280.195.

92. Fielder RL, Carey KB, Carey MP. Acceptability of sexually transmitted infection testing using self-collected vaginal swabs among college women. J Am Coll Health. 2013;61(1):46-53. https://doi.org/10.1080/07448481.2012. 750610

93. France C, Thomas K, Slack R, James N. Psychosocial impacts of chlamydia testing are important. BMJ. 2001;322:1245.

94. Gottlieb SL, Stoner BP, Zaidi AA, Buckel C, Tran M, Leichliter JS, et al. A prospective study of the psychosocial impact of a positive Chlamydia trachomatis laboratory test. Sex Transm Dis. 2011;38(11):1004-11. https://doi. org/10.1097/OLQ.0b013e31822b0bed. 
95. Gotz HM, Veldhuijzen IK, van Bergen JE, Hoebe CJ, de Zwart O, Richardus $\mathrm{JH}$, et al. Acceptability and consequences of screening for Chlamydia trachomatis by home-based urine testing. Sex Transm Dis. 2005;32(9):55762. https://doi.org/10.1097/01.olq.0000175416.15905.db.

96. Stratton KR, Durch JS, Lawrence RS. Vaccines for the 21st century: a tool for decisionmaking. The National Academies Collection: Reports funded by National Institutes of Health. Washington (DC): National Academies Press (US); 2000. http://nationalacademies.org/hmd/Reports/1 999/Vaccines-for-the-21st-Century-A-Tool-for-Decisionmaking.aspx. Accessed 11 Sept 2020

97. Kangas I, Andersen B, Olesen F, Moller JK, Ostergaard L. Psychosocial impact of Chlamydia trachomatis testing in general practice. Br J Gen Pract. 2006; 56(529):587-93.

98. Klovstad H, Natas O, Tverdal A, Aavitsland P. Systematic screening with information and home sampling for genital Chlamydia trachomatis infections in young men and women in Norway: a randomized controlled trial. BMC Infect Dis. 2013;13(1):30. https://doi.org/10.1186/14 71-2334-13-30.

99. Kuppermann M, Learman LA, Schembri M, Gregorich S, Jacoby A, Jackson RA, et al. Effect of noncancerous pelvic problems on health-related quality of life and sexual functioning. Obstet Gynecol. 2007;110(3):633-42. https:// doi.org/10.1097/01.AOG.0000279153.56275.b5.

100. Low N, Connell P, McKevitt C, Baggili T, Tenant-Flowers M, More C, et al. 'You can't tell by looking': pilot study of a community-based intervention to detect asymptomatic sexually transmitted infections. Int J STD AIDS. 2003; 14(12):830-4. https://doi.org/10.1258/095646203322556174.

101. Low N, Egger M, Sterne JA, Harbord RM, Ibrahim F, Lindblom B, et al. Incidence of severe reproductive tract complications associated with diagnosed genital chlamydial infection: the Uppsala Women's Cohort Study. Sex Transm Infect. 2006;82(3):212-8. https://doi.org/10.1136/sti.2005.017186.

102. Mills N, Daker-White G, Graham A, Campbell R. Population screening for Chlamydia trachomatis infection in the UK: a qualitative study of the experiences of those screened. Fam Pract. 2006;23(5):550-7. https://doi. org/10.1093/fampra/cml031.

103. Nielsen A, De Costa A, Danielsson KG, Salazar M. Repeat testing for chlamydia trachomatis, a "safe approach" to unsafe sex? A qualitative exploration among youth in Stockholm. BMC Health Serv Res. 2017;17(1): 730. https://doi.org/10.1186/s12913-017-2681-6.

104. O'Farrell N, Weiss HA. Effect of chlamydia diagnosis on heterosexual relationships. Int J STD AIDS. 2013;24(9):722-6. https://doi.org/10.1177/09564 62413482422 .

105. Ostergaard L, Andersen B, Moller JK, Olesen F. Home sampling versus conventional swab sampling for screening of Chlamydia trachomatis in women: a cluster-randomized 1-year follow-up study. Clin Infect Dis. 2000; 31(4):951-7. https://doi.org/10.1086/318139.

106. Reagan MM, Xu H, Shih SL, Secura GM, Peipert JF. A randomized trial of home versus clinic-based sexually transmitted disease screening among men. Sex Transm Dis. 2012;39(11):842-7. https://doi.org/10.1097/OLQ.0b013 e3182649165.

107. Reed JL, Punches BE, Taylor RG, Macaluso M, Alessandrini EA, Kahn JA. A qualitative analysis of adolescent and caregiver acceptability of universally offered gonorrhea and chlamydia screening in the pediatric emergency department. Ann Emerg Med. 2017;70:787-96.e2.

108. Scholes D, Stergachis A, Heidrich FE, Andrilla H, Holmes KK, Stamm WE. Prevention of pelvic inflammatory disease by screening for cervical chlamydial infection. N Engl J Med. 1996;334(21):1362-6. https://doi.org/10.1 056/NEJM199605233342103.

109. Senok A, Wilson P, Reid M, Scoular A, Craig N, McConnachie A, et al. Can we evaluate population screening strategies in UK general practice? A pilot randomised controlled trial comparing postal and opportunistic screening for genital chlamydial infection. J Epidemiol Community Health. 2005;59(3): 198-204. https://doi.org/10.1136/jech.2004.021584.

110. Smith KJ, Tsevat J, Ness RB, Wiesenfeld HC, Roberts MS. Quality of life utilities for pelvic inflammatory disease health states. Sex Transm Dis. 2008; 35(3):307-11. https://doi.org/10.1097/OLQ.0b013e31815b07dd.

111. Sufrin CB, Postlethwaite D, Armstrong MA, Merchant M, Wendt JM, Steinauer JE. Neisseria gonorrhea and Chlamydia trachomatis screening at intrauterine device insertion and pelvic inflammatory disease. Obstet Gynecol. 2012;120(6): 1314-21. https://doi.org/10.1097/AOG.0b013e318273364c.

112. Theunissen KA, Bos AE, Hoebe CJ, Kok G, Vluggen S, Crutzen R, et al. Chlamydia trachomatis testing among young people: what is the role of stigma? BMC Public Health. 2015;15(1):651. https://doi.org/10.1186/s12889015-2020-y.

113. Trent M, Lehmann HP, Qian Q, Thompson CB, Ellen JM, Frick KD. Adolescent and parental utilities for the health states associated with pelvic inflammatory disease. Sex Transm Infect. 2011;87(7):583-7. https://doi.org/1 0.1136/sextrans-2011-050187.

114. Walker J, Walker S, Fairley CK, Bilardi J, Chen MY, Bradshaw CS, et al. What do young women think about having a chlamydia test? Views of women who tested positive compared with women who tested negative. Sex Health. 2013;10(1):39-42. https://doi.org/10.1071/SH12019.

115. Wilson E, Free C, Morris TP, Syred J, Ahamed I, Menon-Johansson AS, et al. Internet-accessed sexually transmitted infection (e-STI) testing and results service: a randomised, single-blind, controlled trial. PLoS Med. 2017;14(12): e1002479. https://doi.org/10.1371/journal.pmed.1002479.

116. Gaydos CA, Howell MR, Pare B, Clark KL, Ellis DA, Hendrix RM, et al. Chlamydia trachomatis infections in female military recruits. N Engl J Med. 1998;339(11):739-44. https://doi.org/10.1056/NEJM199809103391105.

117. Ostergaard L, Andersen B, Olesen F, Moller JK. Efficacy of home sampling for screening of Chlamydia trachomatis: randomised study. BMJ. 1998; 317(7150):26-7. https://doi.org/10.1136/bmj.317.7150.26.

118. Sufrin C, Postlethwaite D, Armstrong MA, Merchant M, Wendt J, Steinauer J. Comparison of the incidence of pelvic inflammatory disease in intrauterine devices users by gonorrhea and chlamydia screening strategies. Contraception. 2010;82(2):186. https://doi.org/10.1016/j.contraception.2010.04.037.

119. Locadia M, Stalmeier PF, Oort FJ, Prins MH, Sprangers MA, Bossuyt PM. A comparison of 3 valuation methods for temporary health states in patients treated with oral anticoagulants. Med Decis Making. 2004;24(6):625-33. https://doi.org/10.1177/0272989X04271042.

120. Naimer MS, Kwong JC, Bhatia D, Moineddin R, Whelan M, Campitelli MA, et al. The effect of changes in cervical cancer screening guidelines on chlamydia testing. Ann Fam Med. 2017;15(4):329-34. https://doi.org/10.13 70/afm.2097.

121. Bogler T, Farber A, Stall N, Wijayasinghe S, Slater M, Guiang C, et al. Missed connections: unintended consequences of updated cervical cancer screening guidelines on screening rates for sexually transmitted infections. Can Fam Physician. 2015;61(10):e459-66.

122. Lau A, Spark S, Tomnay J, Smith MT, Fairley CK, Guy RJ, et al. Sociodemographic and structural barriers to being tested for chlamydia in general practice. Med J Aust. 2016;204:112.e1-5.

123. Moreira C, Van Gemert C, Hocking JS, Lim MS, Bateson D, McNamee K, et al. Screening for chlamydia concurrently with a routine pap test in primary care: could cervical screening changes impact on chlamydia testing? Sex Transm Infect. 2015;91:A144.

124. Yeung A, Hocking J, Guy R, Fairley CK, Smith K, Vaisey A, et al. 'It Opened My Eyes'-examining the impact of a multifaceted chlamydia testing intervention on general practitioners using Normalization Process Theory. Fam Pract. 2018;28:28.

125. Low N, McCarthy A, Macleod J, Salisbury C, Campbell R, Roberts TE, et al. Epidemiological, social, diagnostic and economic evaluation of population screening for genital chlamydial infection. Health Technol Assess. 2007;11:iiiiv, ix-xii 1-165.

126. Kretzschmar M, van Duynhoven YT, Severijnen AJ. Modeling prevention strategies for gonorrhea and chlamydia using stochastic network simulations. Am J Epidemiol. 1996;144(3):306-17. https://doi.org/10.1093/ oxfordjournals.aje.a008926.

127. Turner KM, Adams EJ, Gay N, Ghani AC, Mercer C, Edmunds WJ. Developing a realistic sexual network model of chlamydia transmission in Britain. Theor Biol Med Model. 2006;3(1):3. https://doi.org/10.1186/1742-4682-3-3.

128. Fajardo-Bernal L, Aponte-Gonzalez J, Vigil P, Angel-Muller E, Rincon C, Gaitan $\mathrm{HG}$, et al. Home-based versus clinic-based specimen collection in the management of Chlamydia trachomatis and Neisseria gonorrhoeae infections. Cochrane Database Syst Rev. 2015;(9):CD011317.

129. Odesanmi TY, Wasti SP, Odesanmi OS, Adegbola O, Oguntuase OO, Mahmood S. Comparative effectiveness and acceptability of home-based and clinic-based sampling methods for sexually transmissible infections screening in females aged 14-50 years: a systematic review and metaanalysis. Sex Health. 2013;10(6):559-69. https://doi.org/10.1071/SH13029.

130. Moher D, Pham B, Klassen TP, Schulz KF, Berlin JA, Jadad AR, et al. What contributions do languages other than English make on the results of meta-analyses? J Clin Epidemiol. 2000;53(9):964-72. https://doi.org/10.1016/ S0895-4356(00)00188-8. 
131. Morrison A, Polisena J, Husereau D, Moulton K, Clark M, Fiander M, et al. The effect of English-language restriction on systematic reviewbased meta-analyses: a systematic review of empirical studies. Int J Technol Assess Health Care. 2012;28(2):138-44. https://doi.org/10.1017/ S0266462312000086.

\section{Publisher's Note}

Springer Nature remains neutral with regard to jurisdictional claims in published maps and institutional affiliations.

Ready to submit your research? Choose BMC and benefit from:

- fast, convenient online submission

- thorough peer review by experienced researchers in your field

- rapid publication on acceptance

- support for research data, including large and complex data types

- gold Open Access which fosters wider collaboration and increased citations

- maximum visibility for your research: over $100 \mathrm{M}$ website views per year

At BMC, research is always in progress.

Learn more biomedcentral.com/submissions 